\title{
INTRA- AND INTERSPECIES DIFFERENCES IN PSEUDO-NITZSCHIA GROWTH AND TOXICITY WHILE USING DIFFERENT NITROGEN SOURCES
}

\author{
A. E. Thessen ${ }^{1}$, H. A. Bowers ${ }^{2}$, D. K. Stoecker ${ }^{1}$ \\ ${ }^{1}$ University of Maryland Center for Environmental Science Horn Point Laboratory, P. O. Box \\ 775, Cambridge, MD 21613 USA \\ ${ }^{2}$ University of Maryland Center for Marine Biotechnology, 701 East Pratt Street, Baltimore, MD \\ 21202 USA
}

*Corresponding author

Current address: Marine Biological Laboratory 7 MBL Street, Woods Hole, MD 02543 USA $\underline{\text { athessen } @ \text { mbl.edu }}$

508-289-7519 (phone)

508-289-7198 (fax)

Submitted to Harmful Algae special issue on strain differences 


\begin{abstract}
Clonal cultures of plankton are widely used in laboratory experiments and have contributed greatly to knowledge of microbial systems. However, many physiological characteristics vary drastically between strains of the same species, calling into question our ability to make ecologically relevant inferences about populations based on studying one or a few strains. This study included nineteen non-axenic strains of three species of the diatom Pseudo-nitzschia isolated primarily from the mid-Atlantic coastal region of the United States. Toxin (domoic acid) production and growth rates were measured in cultures using different nitrogen sources $\left(\mathrm{NH}_{4}{ }^{+}, \mathrm{NO}_{3}{ }^{-}\right.$and urea) and growth irradiances. The strains exhibited broad differences in growth rate and toxin content even between strains isolated from the same water sample. The influence of bacteria on toxin production was not investigated. Both $\underline{\text { P. multiseries }}$ clones produced toxin, yet preferentially used different nitrogen sources. Only two out of nine $\underline{\mathrm{P}}$.

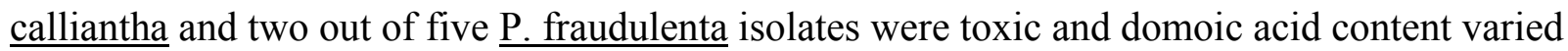
by orders of magnitude. All three species had variable intraspecies growth rates on each nitrogen

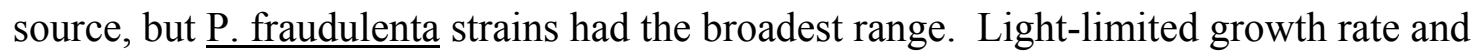

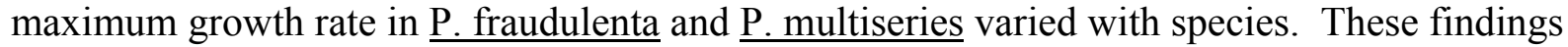
show the importance of defining intra- and interspecies variability in ecophysiology and toxicity. Ecologically relevant functional diversity in the form of ecotypes or cryptic species appears to be present in the genus Pseudo-nitzschia.
\end{abstract}

Keywords: ammonia, diatom, domoic acid, nitrate, Pseudo-nitzschia, urea 


\section{INTRODUCTION}

Much of what we know about plankton physiology comes from experiments using laboratory cultures. Most Pseudo-nitzschia culture studies focus on $\underline{P}$. multiseries with the results extrapolated to other species and strains (Bates 1998). However, broad species and strain differences have been well documented (Gallagher 1980, 1982, Elrifi \& Turpin 1985, Goldman \& Dennett 1985, Holmes et al. 1991, Wood \& Leatham 1992, Larsen \& Bryant 1998, Burkholder et al. 2005) and draw into question the validity of making conclusions about microalgal species physiology based on one or a few strains.

Such high variability among strains casts doubt on the species concept in microalgae in general. While the creation of a species is the result of a biological reality, secondary characteristics are used (frustule morphology, ribosomal genes) to detect and define them. Manhart and McCourt (1992) stated that:

"Practicing phycologists often seem to strive to delineate biological species while basing descriptions solely upon morphological data. The assumption is that morphological species closely approximate biological species of algae, but only rarely is this hypothesis tested. If species assignment is a hypothesis of relationship, then many (perhaps most) implicitly described biological species of algae represent untested hypotheses."

This implies a basic fault in microalgal species definitions which could explain high strain variability. However, Wood and Leatham (1992) argue that difficulties arise when culture studies involving only a few clones are used in an attempt to define interspecies differences without assessing within species variation, not necessarily as the result of a fault in the species 
definition. The number of isolates necessary to accurately define within species variation using statistical methods is difficult to define and restricts the number of studies able to include such an analysis (Lakeman and Cattolico 2007).

The alternative, making conclusions about a species based on one strain, would likely lead to erroneous results. Toxin production in 17 strains of Alexandrium tamarense showed broad differences, the lowest approximating zero mouse units (MU) per $10^{4}$ cells and the highest at 1.1 MU per $10^{4}$ cells (Ogata et al. 1987). No one strain was representative of the species. Taking the analysis one step further, 15 sub-strains taken from one strain had a 0.6 MU per $10^{4}$ cells range in toxin production. An analysis of PSP toxin composition in two strains of $\underline{A}$. tamarense showed that one strain, SB31, produced mostly the sulfocarbamoyl derivative C2 while the other strain, SB32, produced mostly GTX3 and GTX4 (Cembella et al. 2002). Studies such as these show broad differences among strains and argue that finding one "representative" strain is highly unlikely if not impossible. Yet, an analysis of recent publications shows only $40 \%$ of studies that use culture experiments consider the possibility of significant strain differences when making conclusions (Burkholder \& Glibert 2006).

Genetic variability in field populations and strains of Pseudo-nitzschia has been widely documented; however, physiological variability has not been as thoroughly investigated (Evans et al. 2004, Orsini et al. 2004). Many Pseudo-nitzschia culture studies present results from one strain (Bates et al. 1991, Douglas \& Bates 1992, Hillebrand \& Sommer 1996, Pan et al. 1996a,b, Fehling et al. 2004, Armstrong Howard et al. 2007). Others compare one strain of multiple species (Jackson et al. 1992, Hargraves et al. 1993, Wang et al. 1993, Maldonado et al. 2002, 
Fehling et al. 2005). Most studies comparing multiple cultures of one species have focused on

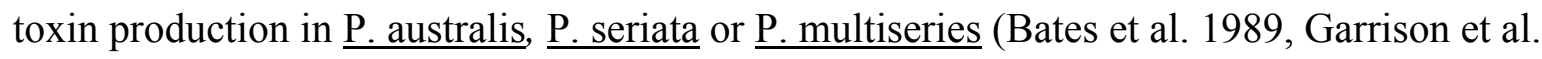
1992, Douglas et al. 1993, Villac et al. 1993, Lundholm et al. 1994, Bates et al. 1999) with one

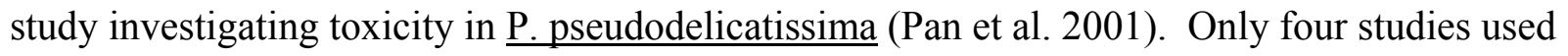
multiple strains of the same species to investigate other physiological processes in addition to

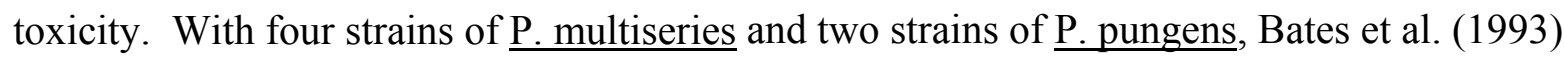
analyzed the effect of $\mathrm{NO}_{3}{ }^{-}$and $\mathrm{NH}_{4}{ }^{+}$on growth and toxin production. Lundholm et al. (2004)

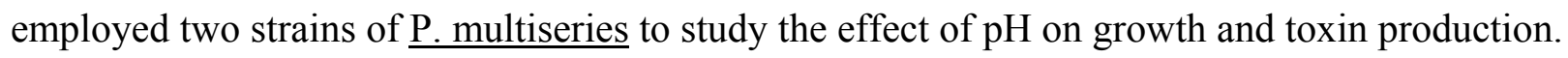
Bates et al. (1995) used three strains of P. multiseries to examine the role of bacteria in domoic acid (DA) production. Thessen et al. (2005) studied two strains of P. delicatissima, two strains of $\underline{P}$. multiseries and three strains of $\underline{P}$. pseudodelicatissima to assess the effect of salinity on growth rate.

Bacterial communities associated with algal cells are increasingly recognized as an important factor in cell physiology that can be highly variable between laboratory strains (Kaczmarska et al. 2005). In Pseudo-nitzschia cultures, biomass and growth rates are not affected by absence or reintroduction of bacteria, but DA production can be 2- to 95 -fold higher in the presence of bacteria (Bates et al. 1995). Studies have verified that Pseudo-nitzschia is the source of DA and bacteria are incapable of producing DA autonomously (Douglas and Bates 1992, Bates et al. 2004). Bacteria play an as yet undefined role in DA production and can have a differential effect among strains and throughout the life of a culture (Stewart 2008). It has been proposed that the amount of DA measured in a culture is the result of competitive interactions between Pseudonitzschia production rate and utilization of DA by extracellular bacteria (Stewart 2008). This, 
instead of genetic variability, could explain measured differences in DA production between Pseudo-nitzschia strains (Stewart 2008).

The meaning of high intraspecific genetic diversity in natural populations is controversial (Fenchel 2005, Foissner 2006). High genetic diversity in some protist taxa has been considered an indicator of cryptic species (species that are identical morphologically, but reproductively isolated) and functional diversity (Dolan 2005, Foissner 2006, Scheckenbach et al. 2006). Others argue that variation in rRNA is an accumulation of neutral mutations that does not correlate with physiology or show biogeographic patterns (Fenchel 2005). However, there have been populations of microalgae comprised of distinct physiological or genetic groupings which showed dynamic seasonal abundances. The presence of multiple ecotypes has been demonstrated in populations of Skeletonema costatum in Narragansett Bay (Gallagher 1980, 1982). These ecotypes have different physiological characteristics, making them better adapted to different environmental conditions and resulting in a succession of ecotypes throughout the year. Similar results have been found with Ditylum brightwellii in Puget Sound (Rynearson et al. 2006). Reproductively isolated cryptic species within $\underline{P \text {. delicatissima and } \underline{P} \text {. }}$ pseudodelicatissima have been identified using morphology, genetic sequences and mating experiments (Amato et al. 2007). The ecological significance of this diversity is not well understood.

This paper is a presentation of strain differences between three species of Pseudo-nitzschia: $\underline{\text { P. }}$

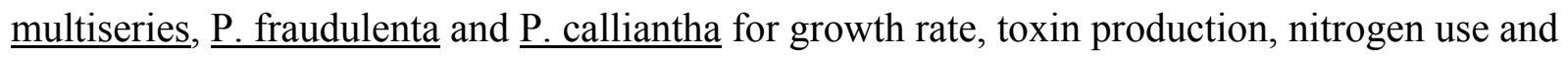


saturating growth irradiance. It is also the first presentation of genetic and toxin data from Chesapeake Bay area Pseudo-nitzschia strains.

\section{MATERIALS AND METHODS}

\section{Culture isolation, identification and maintenance}

Strains of Pseudo-nitzschia spp. were isolated from field samples via micropipetting (Andersen \& Kawachi 2005) and incubated as separate cultures in an inorganic nutrient enriched seawater medium for diatoms, $\mathrm{f} / 2^{*}$ (Andersen et al. 1997), at a temperature and salinity close to ambient conditions at the time and place of collection and a 14:10 L:D cycle (Table 1). Morphological identification was performed using a derivation of methods in Lundholm et al. (2002a). A 10 $\mathrm{mL}$ aliquot of culture was preserved in $1 \%$ gluteraldehyde and digested using $2 \mathrm{~mL}$ of $30 \%$ $\mathrm{H}_{2} \mathrm{SO}_{4}$ and $10 \mathrm{~mL}$ of a saturated $\mathrm{KMnO}_{4}$ solution in a $100 \mathrm{~mL}$ Erlenmeyer flask. The flask was covered with parafilm and swirled periodically throughout the digestion. After $24 \mathrm{~h}$, a saturated oxalic acid solution was added until the sample became transparent. Samples were rinsed 3-4 times with distilled, deionized water and pelleted via centrifugation. The pellet was resuspended in approximately $1 \mathrm{~mL}$ of water. One drop was placed on a $200 \mu \mathrm{m}$ mesh copper grid with a formvar film. Transmission electron microscopy (TEM) was used to identify species of Pseudonitzschia based on frustule morphology from measurements of cell properties in photographic negatives (Skov et al. 1999, Lundholm et al. 2002a,b, Lundholm \& Moestrup 2002, Hasle \& Lundholm 2005).

\section{Genetic and phylogenetic analysis}


DNA extractions from cultures were performed using the Puregene ${ }^{\circledR}$ DNA Isolation Kit (Gentra Systems, Minneapolis, MN). Samples were centrifuged at $4000 \mathrm{~g}$ and the supernatants decanted. Pellets were resuspended in $300 \mu$ of cell lysis buffer supplied with the kit and the manufacturer's protocol was followed for the remainder of the extraction procedure. Eluted DNA was stored at $-20^{\circ} \mathrm{C}$ until analyzed by polymerase chain reaction (PCR).

The nuclear encoded large subunit (D1-D3 region of the LSU; 28S) locus was amplified from Pseudo-nitzschia cultures using two primer sets. Primers D1R forward (Scholin et al. 1994; 5'ACCCGCTGAATTTAAGCATA-3') and LSUSeqRev (5'AGTGCTAGCAACAGACATCAACT-3') resulted in a 517 base pair amplicon, and D3Ca reverse (Scholin et al. 1994; 5' - ACGAACGATTTGCACGTCAG -3') and LSUSeqFor (5' CTGAAACGGAAGCGAAGGAAA-3') resulted in a 434 base pair amplicon. The two amplicons overlapped by 144 base pairs.

The nuclear encoded internal transcribed region (ITS1-5.8S-ITS2) was amplified using two primer sets. Primers 1815F (Bowers et al. 2006; 5'-GGAAGTTGGGGGCAATAACAGG-3') and ITS Rev (Bowers et al. 2006; 5'-CATCGTTGTGGGAACCWAGACAT-3') were used to generate an amplicon from the first half of the ITS region, while ITS For (reverse complement of ITS Rev) and D1R Rev (reverse complement of D1R For mentioned above) were used to generate the second half. Amplicon sizes varied based on the species amplified. These two amplicons did not overlap, so species-specific primers were designed upstream of the ITSFor/Rev primer region to be used in conjunction with D1R Rev in order to generate overlapping sequences: $P$. fraudulenta For (5' - CGTTTGCCTCAAAAGTCAACTTG - 3'); $P$. 
calliantha For (5' - TTTGGCTCGTGACTTTTGTTGC - 3'); and P. multiseries For (5' TTGCCCGCCACTCTTTACGA - 3').

Each $50 \mu 1$ PCR reaction contained 1.5 U of MegaFragTM Taq polymerase (Denville Scientific, Metuchen, $\mathrm{NJ}$ ); 10X PCR buffer and $4 \mathrm{mM} \mathrm{MgCl}_{2}$ supplied with Taq polymerase; $2 \mathrm{mM}$ each dNTP (Invitrogen, Alameda, CA), $0.25 \mathrm{mg} \mathrm{mL}^{-1}$ bovine serum albumin (Idaho Technology, Idaho Falls, ID), $0.8 \mu \mathrm{M}$ each primer (Qiagen/Operon, Alameda, CA), $1 \mu \mathrm{l}$ DNA template and molecular biology grade water to a final volume of $50 \mu \mathrm{l}$. Cycling was performed on the DNA Engine Dyad Peltier Thermocycler (Bio-Rad Laboratories, Inc., Waltham, MA) as follows: initial denaturation at $94^{\circ} \mathrm{C}$ for $2 \mathrm{~min}$, followed by 45 cycles of $94^{\circ} \mathrm{C}$ for $10 \mathrm{~s}$, annealing temperature ranging from $56^{\circ} \mathrm{C}$ to $60^{\circ} \mathrm{C}$ (based on primer pair used) for $30 \mathrm{~s}$, extension step of $68^{\circ} \mathrm{C}$ for $30 \mathrm{~s}$ to $40 \mathrm{~s}$ (depending on amplicon size), and a final extension at $68^{\circ} \mathrm{C}$ for $6 \mathrm{~min} 20 \mathrm{~s}$. PCR products were examined on a $1 \%$ ethidium bromide-stained agarose gel, and bands were extracted from the gel following the procedure supplied with the MinElute kit (Qiagen, Alameda, CA).

All primers outlined above were used for sequencing amplicons. Gel-extracted bands were sequenced using the DYEnamic ${ }^{\mathrm{TM}}$ ET Terminator Cycle Sequencing kit (Amersham Biosciences, Piscataway, NJ). The sequencing reactions contained the following: $2 \mu 1$ dye (diluted 1:5), $1 \mu 1$ of desired primer ( $0.4 \mu \mathrm{M}$ final concentration), 0.5 - $1 \mu \mathrm{l}$ of gel purified product, and sterile $\mathrm{H}_{2} \mathrm{O}$ to $5 \mu 1$. Cycling parameters were as follows: 25 cycles of $95^{\circ} \mathrm{C}$ for $20 \mathrm{~s}, 55^{\circ} \mathrm{C}$ for $15 \mathrm{~s}$ and $60^{\circ} \mathrm{C}$ for 1 min. After cycling, sequencing reactions were centrifuged through Sephadex G50 to remove unincorporated dye (Amersham Biosciences, Uppsala, Sweden). Sequencing was 
performed on the 3100 capillary sequencer (Applied Biosystems, Foster City, CA). Sequences were aligned and inspected for nucleotide ambiguities using Sequencher (version 4.1.2, Gene Codes Corporation, Ann Arbor, MI) and then aligned to other Pseudo-nitzschia species available from GenBank utilizing the software MacClade (version 4.04; Maddison \& Maddison; Sinauer Associates, Inc., Sunderland, MA). The BLAST search program available through the National Center for Biotechnology Information website (www.ncbi.nih.gov/) was used to determine the closest sequence matches available in GenBank (Altschul et al. 1997). Parsimony analysis was performed using PAUP* 4.0b10 (Swofford 2002).

\section{Toxin Content of Cultures}

Potential toxicity of each culture was tested in $\mathrm{f} / 2 *$ medium with $53 \mu \mathrm{M} \mathrm{Si}$ (to induce $\mathrm{Si}$ limitation during stationary phase of growth; Bates et al. 1991, Pan et al. 1991) with bubbling at an irradiance approximating $150 \mu \mathrm{mol}$ photons $\mathrm{m}^{-2} \mathrm{sec}^{-1}$ and a $14: 10 \mathrm{~L}: \mathrm{D}$ cycle in $15^{\circ} \mathrm{C}$ (Bates 1998). In vivo fluorescence of a subsample was measured at the same time daily to monitor growth phase and timing of toxin sample collection. An emphasis was placed on documenting DA concentrations in exponential and stationary phases at least one week after peak fluorescence to capture maximum intracellular toxin (Bates 1998). For the toxin sample, $50 \mathrm{~mL}$ of culture was removed and filtered through a Whatman $\mathrm{GF} / \mathrm{F}$ filter. Both the filter and filtrate were stored at $-80^{\circ} \mathrm{C}$ in the dark for determination of particulate and dissolved toxin. DA is synthesized in the cell and released in variable amounts that increase as the culture ages (Bates et al. 1991, Maldonado et al. 2002). Therefore, both fractions are necessary for quantifying DA production, especially in late stationary phase, when the dissolved fraction is highest (Bates et al. 1991). Care was taken to filter at a low vacuum pressure $(<130 \mathrm{~mm} \mathrm{Hg})$ to avoid breaking cells and 
thus overestimating the dissolved fraction (Bates et al. 1998). Samples were analyzed by high performance liquid chromatography (HPLC; Quilliam 2003) or the ELISA method (Garthwaite et al. 1998) using the ASP direct cELISA test kit (Biosense, Bergen, Norway). HPLC analysis was used to quantify particulate DA initially, but the limit of detection ( $375 \mathrm{pg} \mathrm{DA} \mathrm{mL} \mathrm{L}^{-1}$ ) was too high for many samples. Toxin content in one strain of $\underline{\text { P. multiseries }}(\mathrm{Pn}-1)$ and four strains of P. calliantha (Pn-4, Pn-6, Pn-7 and Pn-8) was determined with this method. The ELISA method has lower limits of detection $\left(9.5-388 \mathrm{pg} \mathrm{mL}^{-1}\right)$ and provided results for more samples, but can have higher variation between replicates. Individual kits have their own quantitation limit ( $\mathrm{LOQ}$ ) and detection limit ( $\mathrm{LOD}=1 / 3$ of $\mathrm{LOQ})$. Concentrations that are below the LOQ, but above the LOD are considered semi-quantitative. The test is positive for DA, but the accuracy is less than if the concentration had been above the LOQ. Since each test kit can process a maximum of 36 samples, not all samples from the same culture could always be processed on the same plate and therefore have the same LOD and LOQ (Table 2).

A preserved sample (1\% gluteraldehyde final concentration) for cell counts was taken with the toxin sample. An aliquot of each preserved sample was stained with $0.03 \%$ proflavin hemisulfate, filtered onto a $2 \mu \mathrm{m}$ polycarbonate filter, and mounted on a glass slide with immersion oil for enumeration via epifluorescent microscopy (excitation 450-490 nm, dichromatic beam splitter $500 \mathrm{~nm}$, barrier filter $515 \mathrm{~nm}$; Nikon filter set EF-4 B-2A) at 400X magnification.

\section{Varying Nitrogen Source}


To test the effect of nitrogen on growth rate and toxin production, each strain was adapted to grow in $\mathrm{f} / 2 *$ with one nitrogen source, $\mathrm{NO}_{3}{ }^{-}, \mathrm{NH}_{4}{ }^{+}$, or urea, and $\mathrm{Si}$ at $\mathrm{f} / 20(88 \mu \mathrm{mol} \mathrm{N}, 11 \mu \mathrm{mol}$ Si) concentrations at $15^{\circ} \mathrm{C}$ with $150-200 \mu \mathrm{mol}$ photons $\mathrm{m}^{-2} \mathrm{sec}^{-1}(14: 10 \mathrm{~L}: \mathrm{D}$ cycle) through two batch cultures as in previous studies (Thessen et al. 2005). When the cultures were adapted, five replicate $125 \mathrm{~mL}$ flasks were inoculated. Chlorophyll a was measured at the same time daily by in vivo fluorescence of a subsample of the flasks and used to calculate specific growth rates (Wood et al. 2005). Toxin and preserved samples were taken one week after the beginning of stationary phase to compare toxin production and cell abundance. Dissolved DA cell ${ }^{-1}$ was calculated by dividing dissolved DA by cell abundance.

Differences in growth rates on each nitrogen source were determined for each strain by one-way ANOVA using Tukey’s studentized range test (SAS®, version 9.1, SAS Institute, Inc., Cary, $\mathrm{NC}, \mathrm{USA}$ ) at the 5\% level. Overall differences among all treatments were analyzed with a model I one-way nested ANOVA with a type III sums of squares where replication was uneven (SPLUS ${ }^{\circledR}$, version 6, Insightful Corporation, Seattle, WA, USA). Variation was determined within nitrogen source, species, strain and error by parsing the sum of squares. Identical statistical analysis was performed on the toxin data. Correlation between growth rate and toxin content was analyzed using Spearman's correlation coefficient (SPLUS®, version 6). Replication is given in Table 3.

\section{Growth versus Irradiance}

Three strains of two species were adapted through two batch culture generations to the experimental temperature $\left(10^{\circ} \mathrm{C}, 15^{\circ} \mathrm{C}\right.$ or $\left.20^{\circ} \mathrm{C}\right)$ and irradiance $\left(20 \mu \mathrm{mol}\right.$ photons $\mathrm{m}^{-2} \mathrm{sec}^{-1}$ to 500 
$\mu \mathrm{mol}$ photons $\mathrm{m}^{-2} \mathrm{sec}^{-1}$ ). The experiment was performed in $\mathrm{f} / 2 *$ media at a salinity of 32 in five replicate $10 \mathrm{~mL}$ glass tubes at each discrete irradiance. Treatments started at $20 \mu \mathrm{mol}$ photons $\mathrm{m}^{-}$ ${ }^{2} \mathrm{sec}^{-1}$ with a 14:10 L:D cycle and increased at approximately $50 \mu \mathrm{mol}$ photons $\mathrm{m}^{-2} \mathrm{sec}^{-1}$ intervals until growth rate saturation. Cultures were monitored daily using in vivo fluorescence. Growth rates were calculated as described above. Replicates were averaged and a standard deviation was calculated. The data were fitted to a non-linear least squares regression using an equation initially derived for photosynthesis (Platt et al. 1980) and modified to describe growth:

$$
\mu=\mu_{o}+\mu_{\max }\left(1-\mathrm{e}^{((-E \alpha) / \mu \max )}\right) \mathrm{e}^{((-E \beta) / \mu \max )}
$$

where $\mu_{\mathrm{o}}$ is the $\mathrm{y}$ intercept, $\mu_{\max }$ is the maximum potential growth rate, $\alpha$ is the initial lightlimited slope, $\mathrm{E}$ is the irradiance and $\beta$ is the slope of the photoinhibited part of the curve. $\mathrm{E}_{\mathrm{k}}$, the irradiance saturating for growth, was calculated for each temperature treatment by dividing $\mu_{\max }$ by $\alpha$. Significant difference between treatments for each regression parameter was calculated using a Gabriel Approximation (Sokal \& Rohlf 1995).

\section{RESULTS}

\section{Identification of Cultures}

Eighteen of nineteen cultures were identified as one of three species: $\underline{P \text {. multiseries, }} \underline{P \text {. calliantha }}$ or P. fraudulenta (Fig. 1; Table 1). Morphometric measurements of the frustules fell within previously reported values for each species (Table 4). ITS and LSU rRNA sequences of the cultures showed identical or close relationships to sequences deposited on GenBank from strains of the same morphological species isolated globally. The P. multiseries culture Pn-1 had 100\% LSU sequence similarity to three strains (NWFSC005 and NWFSC011 from Washington and OFPm984 from Japan) and was two base pairs different from a California isolate CV19 (Fig. 
2A). Pn-1 had $100 \%$ ITS sequence similarity to California strain mu3 and was two base pairs different from the Japanese strain OFPm984 (Fig. 2B). Table 1 provides GenBank accession numbers for LSU and ITS sequences derived from Chesapeake Bay isolate Pn-1.

Sequences for P. fraudulenta cultures Pn-9, Pn-10, Pn-11, Pn-12 and Pn-15 were identical for both the ITS and LSU loci. LSU sequences were identical to those of a strain from Spain, Limens1, and less than ten base pairs different from three strains (SZN-B21, SZN-B40 AND SZN-B22) from Italy (Fig. 2A). The ITS sequence data was two base pairs different from the Spain Limens1 isolate (Fig. 2B). Table 1 provides GenBank accession numbers for LSU and ITS sequences derived from Chesapeake Bay isolates Pn-9, Pn-10, Pn-11, Pn-12 and Pn-15.

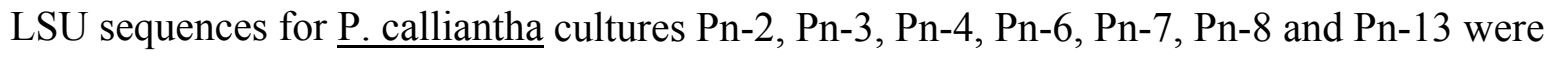
identical, while the ITS sequences exhibited polymorphisms at two positions. Although there

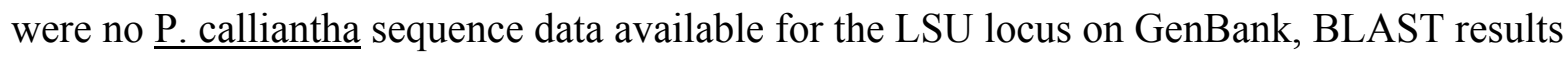

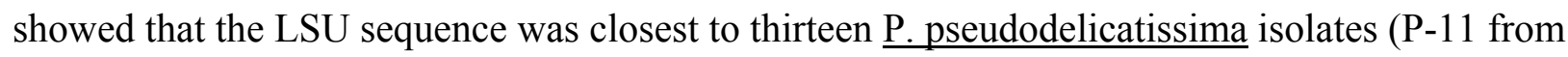
Portugal, NWFSC047, NWFSC040 and NWFSC006 from Washington and the remaining isolates from Italy). There was high genetic variability between all of these isolates, and our sequence showed approximately 0.7 - 5\% divergence from those sequences (Fig. 2A). Our ITS sequences shared $99 \%$ sequence similarity to three P. calliantha isolates from Vietnam (Fig. 2B). Table 1 provides GenBank accession numbers for LSU and ITS sequences derived from Chesapeake Bay isolates Pn-2, Pn-3, Pn-4, Pn-6, Pn-7, Pn-8 and Pn-13.

\section{Toxicity of Cultures}


All batch cultures increased their abundance by at least ten-fold during this experiment. Lag phase, growth rate and time to onset of stationary phase varied. Out of 16 strains tested, seven produced domoic acid (Table 5). All three species cultured had at least two toxic isolates. DA content data is shown normalized to volume $\left(\mathrm{DA} \mathrm{mL}^{-1}\right)$ and cell number (DA cell ${ }^{-1}$ ) for all experiments.

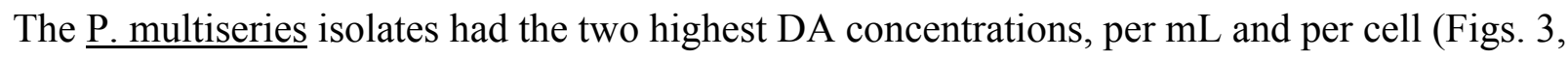
4). P. calliantha and $\underline{P}$. fraudulenta isolates produced between $10^{3}$ and $10^{2} \mathrm{pg} \mathrm{DA} \mathrm{mL} L^{-1}$ (between

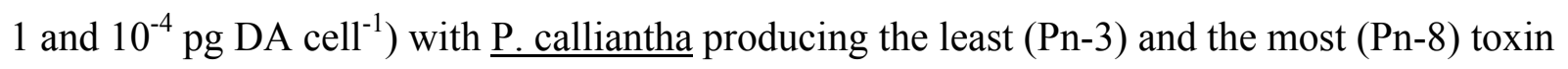
per $\mathrm{mL}$ (Fig. 3). Per cell, $\underline{\mathrm{P} \text {. fraudulenta }}(\mathrm{Pn}-12)$ produced the most $\left(0.16 \mathrm{pg} \mathrm{DA}\right.$ cell $\left.{ }^{-1}\right)$ and $\underline{\mathrm{P}}$. calliantha $(\mathrm{Pn}-3)$ produced the least $\left(2.62 \times 10^{-4} \mathrm{pg}\right.$ DA cell $\left.{ }^{-1}\right)$ amount of toxin (Fig. 4). Growth rates and maximum abundances of strains that did not produce DA were not different from

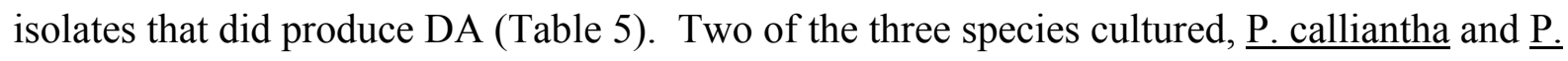
fraudulenta, had non-toxic isolates (Table 5). Three strains of P. calliantha (Pn-2, Pn-5 and Pn18) died within months of isolation, before toxin content was investigated.

The highest total DA levels occurred during stationary phase in all strains. This pattern holds in axenic and non-axenic cultures (Bates et al. 2004). However, in $\underline{\text { P. multiseries and one } \underline{P} \text {. }}$ fraudulenta strain (Pn-12), some DA was also present before stationary phase while the culture

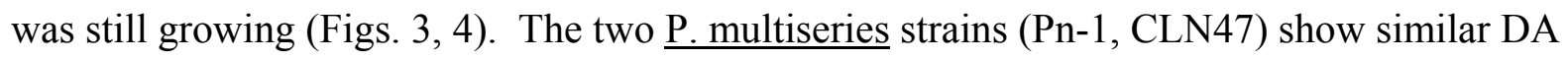
production patterns, with DA present throughout the entire growth cycle, gradually increasing as cell division slowed and reaching a maximum in stationary phase. The two $\underline{\text { P. calliantha strains }}$ (Pn-3, Pn-8) also showed similar DA production patterns with DA produced only once the 


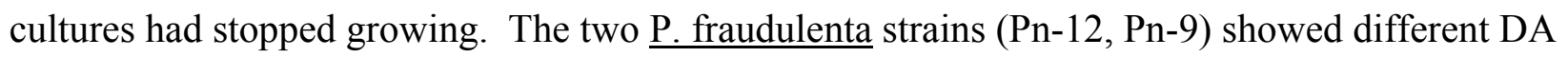
production patterns. One strain (Pn-12) produced DA during late exponential phase while the other (Pn-9) did not produce toxin until stationary phase. DA is a relatively stable molecule under laboratory culture conditions (Bouillon et al. 2006), thus high DA content of the first sample in some strains (Pn-1, CLN47 and Pn-12) is probably carry-over from the inoculum used to start the culture and does not signify any real production of DA in those cultures at the beginning of growth.

\section{Varying Nitrogen Source and Growth Rate}

Nitrogen source $\left(\mathrm{NH}_{4}{ }^{+}, \mathrm{NO}_{3}{ }^{-}\right.$and urea) affected growth rates in Pseudo-nitzschia cultures, but not in a way that could be predicted based on nitrogen source and species (Fig. 5; Table 6). Statistical analysis revealed significant growth rate differences between nitrogen source, species and strain with strain being the highest source and replication the lowest source of variability (Table 6). The two P. multiseries strains had different nitrogen responses, with Pn-1 growing fastest on $\mathrm{NO}_{3}{ }^{-}$and $\mathrm{NH}_{4}{ }^{+}\left(0.75 \mathrm{~d}^{-1}\right)$ while CLN47 grew equally well $\left(0.6 \mathrm{~d}^{-1}\right)$ on all sources. The

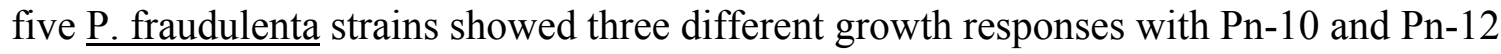
growing fastest on $\mathrm{NO}_{3}{ }^{-}$and $\mathrm{NH}_{4}{ }^{+}\left(0.74-0.88 \mathrm{~d}^{-1}\right)$, while Pn-11 and Pn-15 grew fastest on $\mathrm{NH}_{4}{ }^{+}$ $\left(1.21 \mathrm{~d}^{-1}\right.$ and $1.16 \mathrm{~d}^{-1}$ respectively) and Pn-9 grew fastest on urea $\left(1.02 \mathrm{~d}^{-1}\right)$. The two $\underline{P}$. calliantha strains had different growth responses, but similar growth rates. Pn-13 grew fastest on $\mathrm{NO}_{3}{ }^{-}$and $\mathrm{NH}_{4}{ }^{+}\left(0.7 \mathrm{~d}^{-1}\right)$. Pn-8 grew fastest on $\mathrm{NO}_{3}^{-}\left(0.86 \mathrm{~d}^{-1}\right)$. Nitrogen was an important source of variation in growth rate, but growth was also significantly affected by strain. 
Strains of $\underline{P \text {. multiseries }}(\mathrm{Pn}-1), \underline{\mathrm{P} \text {. fraudulenta }}(\mathrm{Pn}-10)$ and $\underline{\mathrm{P} \text {. calliantha }}(\mathrm{Pn}-13)$, despite being different species, showed similar relative growth responses and growth rates. $\underline{\text { P. fraudulenta }}$ strains isolated from the same water sample (Pn-9, Pn-10, Pn-11 and Pn-12) had the largest differences in relative growth response and growth rate. The only trend in all of these data is higher growth rates on $\mathrm{NH}_{4}{ }^{+}$and lower growth rates on urea, with the exception of one $\underline{\mathrm{P}}$. fraudulenta culture (Pn-9).

\section{Varying Nitrogen Source and Toxicity}

DA concentrations were affected by nitrogen source just as unpredictably as growth rate (Figs. 6, 7; Table 6). Statistical analysis revealed significant differences in toxin content between nitrogen source, species and strain with strain being the highest source of variability in DA content cell ${ }^{-1}$ and $\mathrm{mL}^{-1}$, while for particulate $\mathrm{DA} \mathrm{mL} \mathrm{m}^{-1}$ the highest source of variability is species (Table 6). The only insignificant effect was that of nitrogen on total DA cell ${ }^{-1}$. Two strains of $\underline{\mathrm{P}}$. multiseries produced the most DA while growing on $\mathrm{NH}_{4}{ }^{+}(\mathrm{Pn}-1,3984 \mathrm{fg}$ cell-1 $)$ and $\mathrm{NO}_{3}{ }^{-}$ (CLN47, $369 \mathrm{fg}$ cell $^{-1}$; Tables 5, 7; Figs. 6, 7) and contained the highest total toxin of all strains tested. DA concentration in one strain of $\underline{\mathrm{P} \text {. calliantha }}(\mathrm{Pn}-8)$ and one strain of $\underline{\mathrm{P} \text {. fraudulenta }}$ (Pn-9) did not vary significantly with nitrogen source. One strain of $\underline{\text { P. fraudulenta }}$ (Pn-12) contained more DA while growing on $\mathrm{NH}_{4}{ }^{+}\left(23.7 \mathrm{fg} \mathrm{cell}^{-1}\right)$ and urea $\left(43.3 \mathrm{fg}\right.$ cell $\left.{ }^{-1}\right)$ than $\mathrm{NO}_{3}^{-}$

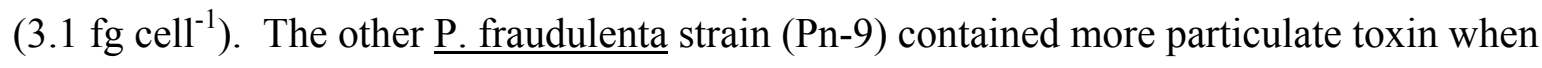
growing on $\mathrm{NO}_{3}^{-}\left(0.29 \mathrm{fg}^{-1 l^{-1}}\right)$. Only the two $\underline{\mathrm{P} \text {. multiseries }}(\mathrm{Pn}-1$ and CLN47) strains always

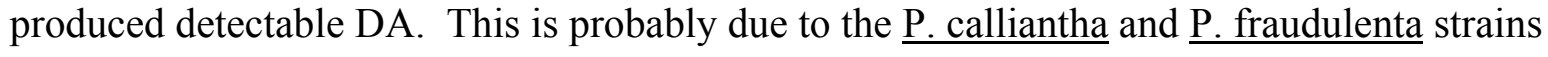
having low toxin content, near the detection limit of the assay, leading to a high error term in the results. 
Growth rates and toxin production did not track each other except in $\underline{\text { P. multiseries }}(\mathrm{Pn}-1)$, where the highest growth rate $\left(0.75 \mathrm{~d}^{-1}\right)$ accompanied the highest toxin content $\left(3984 \mathrm{fg} \mathrm{cell}^{-1}\right)$. Total DA, particulate DA and dissolved DA varied with nitrogen source in both of the $\underline{P \text {. multiseries }}$

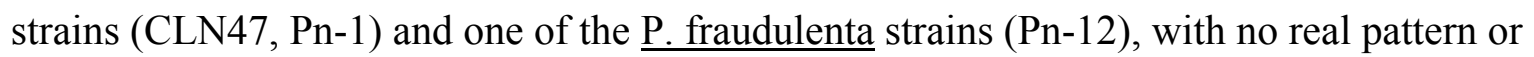
relationship to growth rate (Figs. 8, 9). For example, the highest DA content in CLN47 (371 fg cell ${ }^{-1}$ ) occurred in the $\mathrm{NO}_{3}^{-}$treatment, but growth rate was neither the highest nor the lowest on this nitrogen source. This suggests that nitrogen source has an effect on DA production besides the direct effect on growth rate. Differences in the pattern of toxin content between data given as ng DA mL $\mathrm{m}^{-1}$ (Fig. 8) and fg DA cell ${ }^{-1}$ (Fig. 9) were due to differences in cell number $\mathrm{mL}^{-1}$ at time of sampling and the change from nanograms to femtograms in the unit.

Statistical analysis revealed no significant correlation between growth rate and toxin content for CLN47, Pn-8 and Pn-12 (Table 8). However, growth rate was correlated with dissolved DA normalized to cell number and volume and total DA normalized to cell number in strain Pn-9. Growth rate in Pn-1 was strongly correlated with particulate, dissolved and total DA normalized to both cell number and volume. Toxin content normalized to cell number and volume were nearly identical. CLN47, Pn-1 and Pn-8 showed the same pattern in DA content per cell and per $\mathrm{mL}$. One $\underline{\mathrm{P}}$ fraudulenta strain $(\mathrm{Pn}-12)$ contained more particulate $\mathrm{DA}$ per $\mathrm{mL}$ while growing in $\mathrm{NH}_{4}{ }^{+}$and urea with no significant difference in dissolved DA (0.06-1.18 $\left.\mathrm{ng} \mathrm{mL}{ }^{-1}\right)$. Per cell, there was no significant difference in particulate DA (0-0.78 fg cell $\left.{ }^{-1}\right)$.

\section{Growth versus Irradiance}


Growth versus irradiance experiments were performed on three strains of two species at three temperatures (Fig. 10). P. fraudulenta (Pn-15) would not grow at all light levels at all temperatures; therefore the curve at $20^{\circ} \mathrm{C}$ is incomplete. Curve parameters $\alpha\left(\mathrm{d}^{-1}[\mu \mathrm{mol}\right.$ photons $\left.\left.\mathrm{m}^{-2} \sec ^{-1}\right]^{-1}\right)^{\dagger}$ and $\mu_{\max }\left(\mathrm{d}^{-1}\right)$ showed significant differences between species at the same temperature (Table 9). At $10^{\circ} \mathrm{C}, \alpha\left(0.0263 \mathrm{~d}^{-1}\left[\mu \mathrm{mol} \text { photons } \mathrm{m}^{-2} \mathrm{sec}^{-1}\right]^{-1}\right)$ in $\underline{\mathrm{P} \text {. fraudulenta was }}$ different from $\alpha$ in the P. multiseries strains (Pn-1 and CLN47) which were not different from each other $\left(0.0067,0.0127 \mathrm{~d}^{-1}\left[\mu \mathrm{mol} \text { photons } \mathrm{m}^{-2} \mathrm{sec}^{-1}\right]^{-1}\right.$ respectively). At $15^{\circ} \mathrm{C}, \alpha$ in $\underline{\mathrm{P}}$. fraudulenta $\left(0.0239 \mathrm{~d}^{-1}\left[\mu \mathrm{mol} \text { photons } \mathrm{m}^{-2} \mathrm{sec}^{-1}\right]^{-1}\right)$ was different from only one of the $\underline{\mathrm{P}}$. multiseries strains $\left(0.0047 \mathrm{~d}^{-1}\left[\mu \mathrm{mol} \text { photons } \mathrm{m}^{-2} \sec ^{-1}\right]^{-1}, \mathrm{Pn}-1\right)$ which were not different from each other $\left(0.0109 \mathrm{~d}^{-1}\left[\mu \mathrm{mol} \text { photons } \mathrm{m}^{-2} \sec ^{-1}\right]^{-1}\right.$, CLN47). At $20^{\circ}, \alpha$ was not significantly different between strains of P. multiseries $\left(0.0094-0.0098 \mathrm{~d}^{-1}\left[\mu \mathrm{mol} \text { photons } \mathrm{m}^{-2} \mathrm{sec}^{-1}\right]^{-1}\right.$; Table 9). Alpha was not significantly different between temperatures within the same strain. At $10^{\circ} \mathrm{C}$, $\mu_{\max }\left(\mathrm{d}^{-1}\right)$ did not show any difference between strains. At $15^{\circ} \mathrm{C}$, however there was a difference in $\mu_{\max }$ between $\underline{\text { P. fraudulenta }}(0.68)$ and one of the $\underline{\text { P. multiseries }}$ strains $(0.33$, CLN47). There was no statistically significant difference between $\mu_{\max }$ at $20^{\circ} \mathrm{C}(0.78-2.0)$, probably due to the high variability in $\underline{\mathrm{P} \text {. multiseries }}(\mathrm{Pn}-1)$. None of the strains showed significant changes with temperature. Comparisons of $\beta$ were not possible because not all strains were photoinhibited. Saturating irradiance $\left(E_{k}\right)$ was calculated for each treatment where possible, but had such high variability that none of the data were significant (Table 9).

\section{DISCUSSION}

\footnotetext{
${ }^{\dagger}$ Unit for $\alpha$ reduces to $\mu$ mol photons $\mathrm{m}^{-2} * 86400$. While conceptually correct, this method uses unusual units because $\alpha$ is typically used to describe P vs. E curves instead of $\mu$ vs. E curves.
} 
Sequences for the LSU (large subunit of the ribosome) and ITS (internal transcribed spacer) regions were successfully combined with morphology to identify Pseudo-nitzschia strains to species level. Both morphological and genetic data were conclusive and consistent for

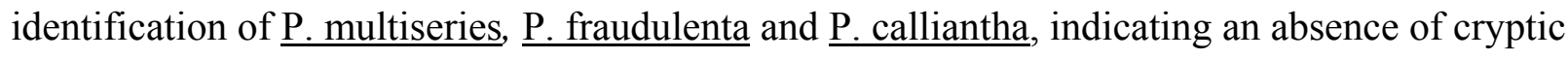
or sibling species within those groups. However, these isolates were probably only a small representation of a more genetically diverse Pseudo-nitzschia population in the Chesapeake Bay. In fact, real-time molecular assays designed against the three species isolated from the Bay only identified these species in a small percentage of environmental water samples where Pseudonitzschia had been identified using light microscopy (data not shown). Field studies using rRNA sequences and microsatellite markers have found high genetic diversity in Pseudo-nitzschia populations (Orsini et al. 2004, Evans et al. 2005). The high divergence between strains of $\underline{P}$. calliantha and the P. pseudodelicatissima in GenBank (0.7-5\%) is indicative of the pseudodelicatissima species complex that was recently partially resolved based on morphology and genetics (Lundholm et al. 2003) and may still need further resolution. The lack of such variability in Pseudo-nitzschia cultures world-wide could be an artifact of the culturing process favoring strains with similar genetics (Ward et al. 1990, Amann et al. 1995). Alternate locus sequencing or microsatellite analysis could reveal more diversity in cultures. Physiological parameters tested in this study were not consistently related to species, suggesting the presence of ecotypes and high functional diversity in the species tested. Genetic and functional diversity among and within Pseudo-nitzschia species needs to be explored further in order to gain a better understanding of the strains present and how they are related to natural populations. 


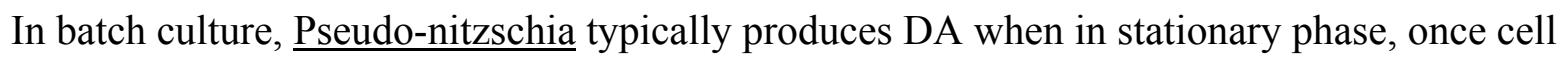
division has stopped and the culture is limited by $\mathrm{P}$ or $\mathrm{Si}$, for example, with replete $\mathrm{N}$ and light (Bates 1998). This is seen in Pn-1, Pn-3, Pn-8 and Pn-9 as well as in other studies with $\underline{P}$.

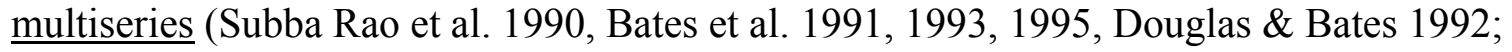
Wohlgeschaffen et al. 1992, Douglas et al. 1993, Whyte et al. 1995, Kotaki et al. 1999,

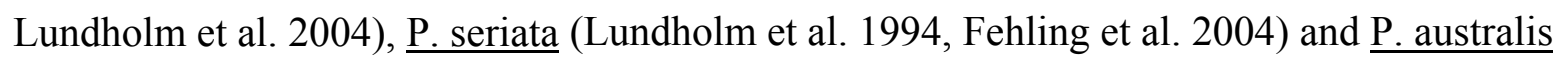
(Cusack et al. 2002). In CLN47 and Pn-12, there is evidence of toxin production during late

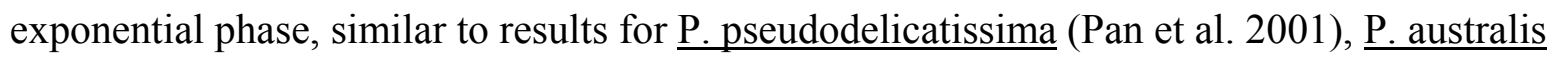
(Garrison et al. 1992) and for P. multiseries (Pan et al. 1996a). A possible explanation for DA production in late exponential phase, before the culture has stopped growing, is that this phase may be a period of transition, when some cells have stopped dividing and are producing DA while others are still growing (Pan et al. 1996a, Bates 1998). High DA content during lag phase is probably from the inoculum used to start the culture; however, it is possible that the shock of being transferred led to DA production in lag phase cultures (Bates 1998). It is also generally assumed that particulate DA peaks about one week after the beginning of stationary phase, then decreases as dissolved DA increases (Bates 1998). Total DA content did not peak in any of our cultures within the $26 \mathrm{~d}$ duration of the experiment, with the exception of Pn-12.

It is generally thought that $\mathrm{NH}_{4}^{+}$is more readily taken up by phytoplankton than $\mathrm{NO}_{3}{ }^{-}$due to its inhibition of nitrate reductase and lower energy requirement for use (McCarthy et al. 1977, Losada \& Guerrero 1979, Syrett 1981). However, studies have shown that inhibition of $\mathrm{NO}_{3}^{-}$ uptake is rarely as complete or as common as sometimes believed (reviewed in Dortch 1990). Uptake and reduction of $\mathrm{NO}_{3}{ }^{-}$can be decoupled due to the much lower amount of energy 
required to take up $\mathrm{NO}_{3}{ }^{-}$compared to reducing $\mathrm{NO}_{3}{ }^{-}$. When temperatures are low, nitrate reduction enzymes are limited (Lomas and Glibert 2000). Diatoms in particular take up large amounts of $\mathrm{NO}_{3}^{-}$under high light, low temperature conditions, resulting in large internal pools (DeManche et al. 1979, Dortch et al. 1979, Collos 1982, Lomas \& Glibert 1999, 2000). Diatoms are known to grow equally well on $\mathrm{NH}_{4}{ }^{+}$and $\mathrm{NO}_{3}{ }^{-}$(Eppley \& Renger 1974) and studies on phytoplankton assemblages show utilization of whatever nitrogen source is readily available (McCarthy et al. 1977, Dortch 1990). Uptake rates of $\mathrm{NO}_{3}{ }^{-}, \mathrm{NH}_{4}{ }^{+}$and urea by diatoms vary considerably and depend on the physiological state of the cell, but uptake of all three nitrogen species in diatoms has been documented (Eppley et al. 1969, McCarthy 1972).

These results demonstrate the ability of Pseudo-nitzschia to grow and become toxic on multiple

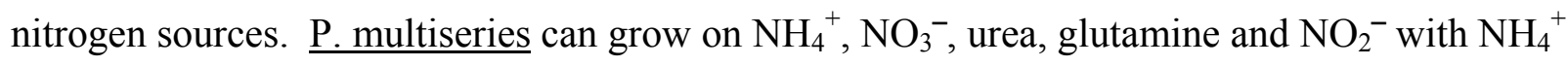
supporting the slowest growth (Hillebrand \& Sommer 1996). $\mathrm{NH}_{4}{ }^{+}$concentrations above 200 $\mu \mathrm{M}$ do not support growth due to $\mathrm{NH}_{4}{ }^{+}$toxicity (Hillebrand \& Sommer 1996), and only at $\mathrm{NH}_{4}{ }^{+}$ concentrations of $55-110 \mu \mathrm{M}$ were growth rates comparable to those in $\mathrm{NO}_{3}{ }^{-}$(Bates et al. 1993). The present study used $88 \mu \mathrm{M}$ nitrogen. Growth rates $\left(\mathrm{d}^{-1}\right)$ for $\underline{\mathrm{P} \text {. multiseries }}$ were slightly less $\left(0.36-0.33\right.$ for $300 \mu \mathrm{M} \mathrm{NH}_{4}{ }^{+}, 0.42-0.55$ for $200 \mu \mathrm{M} \mathrm{NO}_{3}{ }^{-}$and $0.38-0.60$ for 200 $\mu \mathrm{M}$ urea $)$ than those in our experiments $\left(0.61-0.76\right.$ for $\mathrm{NH}_{4}{ }^{+}, 0.45-0.8$ for $\mathrm{NO}_{3}{ }^{-}$and $0.3-0.68$ for urea; Hillebrand \& Sommer 1996). A study of cultured $\underline{P}$. australis (using $50 \mu \mathrm{M}$ nitrogen) showed equal growth on $\mathrm{NO}_{3}{ }^{-}$and $\mathrm{NH}_{4}{ }^{+}$, but reduced growth on urea, with the latter culture containing the highest DA (Armstrong Howard et al. 2007). This is unlike any of the present cultures, except Pn-12 ( $\underline{\mathrm{P} . \text { fraudulenta}})$. Another study showed higher DA content in $\underline{\mathrm{P}}$. $\underline{\text { multiseries treated with } 440 \mu \mathrm{M} \mathrm{NH}_{4}{ }^{+} \text {than } 440 \mu \mathrm{M} \mathrm{NO}_{3}^{-}\left(4.2 \mathrm{pg} \mathrm{cell}^{-1} \text { in } \mathrm{NH}_{4}{ }^{+} \text {and } \sim 1.6 \mathrm{pg}^{-} \text {cell }\right.}$ 
${ }^{1}$ in $\mathrm{NO}_{3}^{-}$; Bates et al. 1993) which is comparable to the DA content in $\underline{\mathrm{P} \text {. multiseries }}(\mathrm{Pn}-1)$ in our study (4.0 pg cell ${ }^{-1}$ when grown in $\mathrm{NH}_{4}{ }^{+}$and $1.9 \mathrm{pg}$ cell $^{-1}$ when grown in $\left.\mathrm{NO}_{3}^{-}\right)$. These data show that specific growth rate and toxin content of Pseudo-nitzschia can be affected by nitrogen source, but cannot be predicted based on nitrogen and species. There is clearly no strain in this study that is representative of the growth response or toxin content of the genus or any of the three species.

There are two important concerns with the toxin samples for the nitrogen experiments. First, even though all cultures were sampled at the same time relative to their growth phase, one week after the fluorescence peak is not enough time for these strains to reach maximum DA content (Fig. 3). Some of the variation between treatment, species and/or strain could be due instead to time of sample collection relative to DA production cycle in batch culture. Second, working with very low amounts of DA on multiple ELISA plates could have resulted in the unusual zero values in $\underline{\mathrm{P} . \text { fraudulenta }}(\mathrm{Pn}-12)$ and $\underline{\mathrm{P} . \text { calliantha }}(\mathrm{Pn}-8)$.

Statistical analysis (ANOVA) revealed that most variation in toxin content and growth rate is due to strain (except particulate $\mathrm{DA} \mathrm{mL}^{-1}$ ), arguing that strain is more important than species in defining the physiology of Pseudo-nitzschia. However, species was the second most important source of variation. If more species were included in this study, especially more toxic species, this relative importance could shift so that species is more important than strain. The actual treatment, nitrogen source, resulted in the lowest source of variation in toxin content and growth rate, sometimes lower than the replicate cultures (particulate DA and total DA cell ${ }^{-1}$ ), but it was responsible for a higher proportion of variation in growth rate than in toxin content. Nitrogen 
source had more of an effect on particulate and total DA mL ${ }^{-1}$ than DA cell ${ }^{-1}$, suggesting that the affect of nitrogen source on toxin content is an indirect effect of growth rate on cell abundance.

Most of the variation in toxin content in this study can be attributed to strain differences, indicating that intraspecies variation is larger than interspecies variation especially among low toxin-producing species. In this context "strain differences" can be genetic differences or differences in bacterial flora within the culture. We did not address variation in epibiotic bacteria, a potential source of variation in toxin levels. For example, two cultures of the same strain (CLN-1 and CLN-1 NRC) of P. multiseries that had been maintained in separate laboratories for 2 years differed in their epibiotic bacteria and toxin production (Kaczmarska et al. 2005). The culture with more diverse bacterial flora produced the most DA (CLN-1). It is unlikely that changes in DA production within batch cultures over the growth cycle are due to bacteria because both axenic and non-axenic cultures show the same pattern of increased DA production in stationary phase (Bates et al. 1995). It is also unlikely that differences in DA content between nitrogen treatments in this study are due solely to bacteria because of the shorter time passed between subculturing and experimentation (months rather than years). However, differences in toxin content between strains of the same species in this study could be affected by bacteria.

Previous studies showed a relationship between growth rate and DA content using one strain of

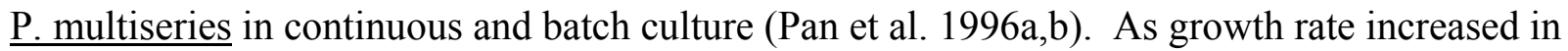
continuous cultures, DA content decreased. This study found an inverse relationship between growth rate and toxin content only in Pn-9 (Table 8). Growth rate and toxin content in Pn-1 was 
found to be positively correlated and no relationship was found in the other strains. However, these experiments were performed on stationary phase batch cultures, which are different from slowly growing continuous cultures.

The growth versus irradiance curves seem to show differences in $\alpha$ and $\mu_{\max }$ among temperature treatments (Fig. 10). However, high variability associated with the $20^{\circ} \mathrm{C}$ treatments render these differences statistically insignificant (Table 9). Using a turbidostat to calculate a growth vs. irradiance curve (Falkowski et al. 1985) instead of using replicate batch cultures at discrete irradiances could result in less error. Replication could be achieved by collecting data for multiple curves instead of replicates of points on a single curve. Only one other study contains $\mu$ vs. E data for Pseudo-nitzschia (Pan et al. 1996b), where an $\alpha$ of $0.0027 \mathrm{~d}^{-1}\left[\mu \mathrm{mol}\right.$ photons $\mathrm{m}^{-2}$

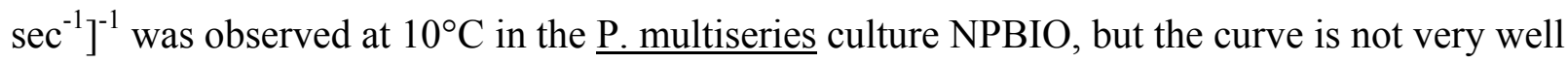
described below $200 \mu \mathrm{mol}$ photons $\mathrm{m}^{-2} \mathrm{sec}^{-1}$, the light-limiting part of the curve in that study (Fig. 10). Nevertheless, the $\alpha$ is within the range observed for $\underline{\text { P. multiseries }}$ in the present experiments (Table 9). The incomplete curve at $20^{\circ} \mathrm{C}$ for Pn-15 (Fig. 10) can be explained by intolerance of this strain to higher temperatures; this strain would not adapt to $20^{\circ} \mathrm{C}$ at low irradiance. Pn-15 was isolated from cold waters (Table 1) and could represent an ecotype that is adapted to survive at low temperatures. Pn-15 had its highest growth rates at $10^{\circ} \mathrm{C}$ (Fig. 10). A

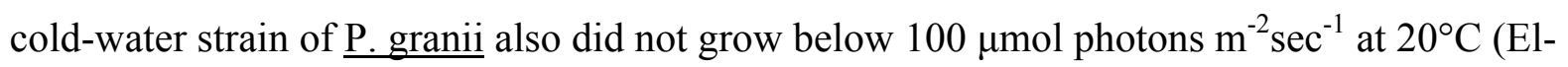

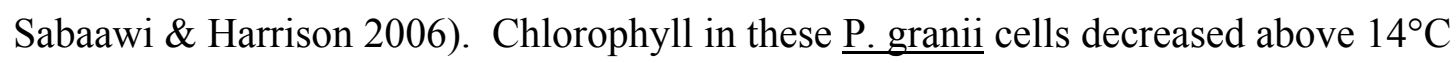
suggesting that the decline in growth rate at lower irradiance may have been due to an inability to capture adequate light to support increased enzyme activity associated with higher temperatures (El-Sabaawi \& Harrison 2006). 
There was concern that results might be affected by differences over time in culture as many physiological properties have been known to change with culture age, especially Pseudonitzschia toxin production (Bates et al. 1999). As an individual batch culture of harmful algae ages and approaches stationary growth toxin production typically increases (Bates et al. 1998, Dias et al. 2002). Additional parameters such as growth rate, chlorophyll fluorescence and lipid composition are known to increase or decrease throughout the growth cycle of a batch culture, but often return to previous values when a new batch culture is started (Mansour et al. 2003, Liang et al. 2006). Long-term physiological changes are likely to occur when a strain is held in the laboratory for several years. Pseudo-nitzschia strains typically lose toxicity the longer they are grown in the laboratory, possibly due to interactions with bacteria flora (Stewart 2008), which can change as the strain ages (Kaczmarska et al. 2005). Most of the cultures were approximately the same age (one year) during this study (Table 10).

Results do support the following: Defining diatom species based on morphology alone can be inadequate. A more thorough approach is required which includes morphological investigations, genetic sequencing, mating experiments and physiological experiments (Mann 1999). Numerous Pseudo-nitzschia spp. have been described by combinations of morphology and gene sequences (Lundholm et al. 2002a,b, 2003, 2006, Lundholm \& Moestrup 2002). Only one Pseudo-nitzschia study combines morphology, genetic sequencing and mating experiments (Amato et al. 2007). As the impact of strain differences is recognized, diatom studies should include an investigation of the biological and phylogenetic species concepts in addition to the more traditional morphological species concept (e.g., Behnke et al. 2004, Mann et al. 2004). 
The ability of Pseudo-nitzschia to grow under multiple nitrogen, light and temperature conditions indicates a broad ecological niche, which reflects the cosmopolitan nature of the genus. Not all strains were able to grow optimally under all treatments, but at least one strain did grow optimally under all conditions tested. This, in combination with high genetic variability in natural populations (Evans et al. 2005), suggests that Pseudo-nitzschia is able to take advantage of multiple regimes in a changing environment. For example, a species of Pseudo-nitzschia might be present in a system throughout the spring and appear to be static, but genetic or physiological analyses would reveal a dynamic succession of subpopulations as environmental parameters changed and favored different ecotypes. These data suggest the existence of multiple ecotypes in natural populations of Pseudo-nitzschia, similar to $\underline{\text { Skeletonema costatum }}$ and Ditylum brightwellii (Gallagher 1982, Rynearson et al. 2006). Since all of the strains tested in this study came from the same region, nothing can be concluded about biogeography; however, it

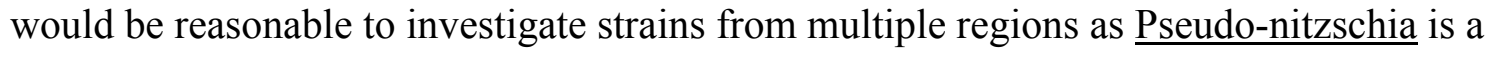
cosmopolitan diatom genus (Hasle 2002).

\section{ACKNOWLEDGEMENTS}

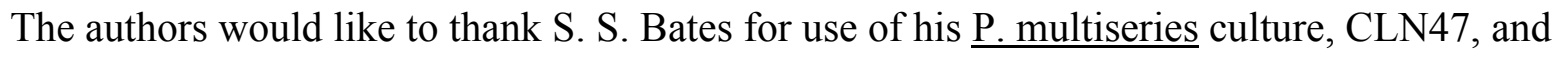
SEM micrographs, E. Gantt for assistance with electron microscopy, D. Caron and A. Schnetzer for assistance with the ELISA procedure, P. M. Glibert, K. G. Sellner and J. M. O’Neil for commenting on early drafts and two anonymous reviewers for their valuable editorial comments. This research was supported by EPA STAR fellowship program FP916343 (A.E.T) and funding 
through the Centers for Disease Control (H.A.B); DHMH OCPMP 048315G/M00B400298. This manuscript has not been formally reviewed by the EPA. The views expressed in this document are solely those of the author, and the EPA does not endorse any products or commercial services mentioned in this publication. This is UMCES contribution No. 4244. 


\section{LITERATURE CITED}

Altschul, S.F., Madden, T.L., Schaffer, A.A., Zhang, J.H., Zhang, Z., Miller, W., Lipman, D.J., 1997. Gapped BLAST and PSI-BLAST: a new generation of protein database search programs. Nucleic Acids Res. 25(17), 3389-3402.

Amann, R. I., Ludwig, W., Schleifer, K. H., 1995. Phylogenetic identification and in situ detection of individual microbial cells without cultivation. Microbiol. Rev. 59:143-169.

Amato, A., Kooistra, W.H.C.F., Ghiron, J.H.L., Mann, D.G., Proschold, T., Montresor, M., 2007. Reproductive isolation among sympatric cryptic species in marine diatoms. Protist. 158(2), 193-207.

Andersen, R.A., Morton, S.L., Sexton, J.P., 1997. Provasoli-Guillard national center for culture of marine phytoplankton 1997 list of strains. J. Phycol. 33S(6), 1-75.

Andersen, R.A., Kawachi, M., 2005. Traditional microalgae isolation techniques. In: Andersen, R.A. (Ed.), Algal Culturing Techniques. Acadamic Press, New York, pp. 83-100.

Armstrong Howard, M.D., Cochlan, W.P., Ladizinsky, N., Kudela, R.M., 2007. Nitrogenous preference of toxigenic Pseudo-nitzschia australis (Bacillariophyceae) from field and laboratory experiments. Harmful Algae. 6(2), 206-217.

Bates, S.S., 1998. Ecophysiology and metabolism of ASP toxin production. In: Hallegraeff, G.M. (Ed.), Physiological Ecology of Harmful Algal Blooms. Springer-Verlag, Berlin, pp. 405426.

Bates, S.S., Bird, C.J., de Freitas, A.S.W., Foxall, R., Gilgan, M., Hanic, L.A., Johnson, G.R., McCulloch, A.W., Odense, P., Pocklington, R., Quilliam, M., Sim, J., Smith, J.C., Subba Rao, D.V., Todd, E.C.D., Walter, J.A., Wright, J.L.C., 1989. Pennate diatom Nitzschia pungens as the primary source of domoic acid, a toxin in shellfish from eastern Prince Edward Island, Canada. Can. J. Fish. Aquat. Sci. 46(7), 1203-1215.

Bates, S.S., Freitas, A., Milley, J.F., Pocklington, R., Quilliam, M.A., Smith, J.C., Worms, J., 1991. Controls on domoic acid production by the diatom Nitzschia pungens f. multiseries in culture: Nutrients and irradiance. Can. J. Fish. Aquat. Sci. 48(7), 1136-1144.

Bates, S.S., Worms, J., Smith, J.C., 1993. Effects of ammonium and nitrate on growth and domoic acid production by Nitzschia pungens in batch culture. Can. J. Fish. Aquat. Sci. 50(6), $1248-1254$.

Bates, S.S., Douglas, D.J., Doucette, G.J., Leger, C., 1995. Enhancement of domoic acid production by reintroducing bacteria to axenic cultures of the diatom Pseudo-nitzschia multiseries. Nat. Toxins. 3(6), 428-435. 
Bates, S.S., Hiltz, M.F., Leger, C., 1999. Domoic acid toxicity of large new cells of Pseudonitzschia multiseries resulting from sexual reproduction. Proceedings of the Sixth Canadian Workshop on Harmful Marine Algae, Ottowa ON, Feb 1999, pp.21-26.

Bates, S. S., Gaudet, J., Kaczmarska, I., Ehrman, J. M., 2004. Interaction between bacteria and the domoic-acid-producing diatom Pseudo-nitzschia multiseries (Hasle) Hasle; can bacteria produce domoic acid autonomously? Harmful Algae 3(1), 11-20.

Behnke, A., Friedl, T., Chepurnov, V.A., Mann, D.G., 2004. Reproductive compatibility and rDNA sequence analyses in the Sellaphora pupula species complex (Bacillariophyta). J. Phycol. 40(1), 193-208.

Bouillon, R. C., Knierim, T. L., Kieber, R. J., Skrabal, S. A., Wright, J. L. C., 2006. Photodegradation of the algal toxin domoic acid in natural water matrices. Limnol. Oceanogr. 51(1), 321-330.

Bowers, H.A., Tomas, C., Tengs, T., Kempton, J., Lewitus, A., Oldach, D.W., 2006. Raphidophyceae (Chadefaud ex Silva) systematics and rapid identification: sequence analyses and real time PCR assays. J. Phycol. 42(6), 1333-1348.

Burkholder, J. M., Gordon, A. S., Moeller, P. D., Mac Law, J., Coyne, K. J., Lewitus, A. J., Ramsdell, J. S., Marshall, H. G., Deamer, N. J., Cary, S. C., Kempton, J. W., Morton, S. L., Rublee, P. A. 2005. Demonstration of toxicity to fish and to mammalian cells by Pfiesteria species: comparison of assay methods and strains. Proc. Natl. Acad. Sci. 102(9), 3471-3476.

Burkholder, J.M., Glibert, P.M., 2006. Intraspecific variability: an important consideration in forming generalizations about toxigenic algal species. Afr. J. of Mar. Sci. 28(2), 177-180.

Caroppo, C., Congestri, R., Bracchini, L., Albertano, P., 2005. On the presence of Pseudonitzschia calliantha Lundholm, Moestrup et Hasle and Pseudo-nitzschia delicatissima (Cleve) Heiden in the Southern Adriatic Sea (Mediterranean Sea, Italy). J. Plankton Res. 27(8), 763-774.

Cembella, A.D., Quilliam, M.A., Lewis, N.I., Bauder, A.G., Dell'Aversano, C., Thomas, K., Jellet, J., Cusack, R.R., 2002. The toxigenic marine dinoflagellate Alexandrium tamarense as the probable cause of mortality of caged salmon in Nova Scotia. Harmful Algae. 1, 313-325.

Collos, Y., 1982. Transient Situations in Nitrate Assimilation by Marine Diatoms - Short-Term Uncoupling of Nitrate Uptake and Reduction. J. Exp. Mar. Biol. Ecol. 62(3), 285-295.

Cusack, C.K., Bates, S.S., Quilliam, M.A., Patching, J.W., Raine, R., 2002. Confirmation of domoic acid production by Pseudo-nitzschia australis (Bacillariophyceae) isolated from Irish waters. J. Phycol. 38(6), 1106-1112.

DeManche, J.M., Curl, H.C., Jr., Lundy, D.W., Donaghay, P.L., 1979. The rapid response of the marine diatom Skeletonema costatum to changes in external and internal nutrient concentration. Mar Biol. 53(4), 323-333. 
Dias, E., Pereira, P., Franca, S., 2002. Production of paralytic shellfish toxins by Aphanizomenon sp. LMECYA 31 (cyanobacteria). J. Phycol. 38(4), 705-712.

Dolan, J.R., 2005. An introduction to the biogeography of aquatic microbes. Aquat. Microb. Ecol. 41(1), 39-48.

Dortch, Q., 1990. The interaction between ammonium and nitrate uptake in phytoplankton. Mar Ecol Prog Ser. 61(1-2), 183-201.

Dortch, Q., Ahmed, S.I., Packard, T.T., 1979. Nitrate reductase and glutamate dehydrogenase activities in Skeletonema costatum as measures of nitrogen assimilation rates. 1(2), 169-186.

Douglas, D.J., Bates, S.S., 1992. Production of domoic acid, a neurotoxic amino acid, by an axenic culture of the marine diatom Nitzschia pungens f. multiseries Hasle. Can. J. Fish. Aquat. Sci. 49(1), 85-90.

Douglas, D.J., Bates, S.S., Bourque, L.A., Selvin, R.C., 1993. Domoic acid production by axenic and non-axenic cultures of the pennate diatom Nitzschia pungens $f$. multiseries. In: Shimizu, Y. (Ed.), Toxic Phytoplankton Blooms in the Sea. Elsevier, Amsterdam, pp. 595-600.

Elrifi, I.R., Turpin, D.H., 1985. Transient photosynthetic responses of nitrogen limited microalgae to nitrogen addition. Mar. Ecol. Prog. Ser. 20(3), 253-258.

El-Sabaawi, R., Harrison, P.J., 2006. Interactive effects of irradiance and temperature on the photosynthetic physiology of the pennate diatom Pseudo-nitzschia granii (Bacillariophyceae) from the northeast subarctic pacific. J. Phycol. 42(4), 778-785.

Eppley, R.W., Renger, E.H., 1974. Nitrogen assimilation of an oceanic diatom in nitrogenlimited continuous culture. J. Phycol. 10(1), 15-23.

Eppley, R.W., Rogers, J.N., Mccarthy, J.J., 1969. Half-saturation constants for uptake of nitrate and ammonium by marine phytoplankton. Limnol. Oceanogr. 14(6), 912-920.

Evans, K.M., Bates, S.S., Medlin, L.K., Hayes, P.K., 2004. Microsatellite marker development and genetic variation in the toxic marine diatom Pseudo-nitzschia multiseries (Bacillariophyceae). J. Phycol. 40(5), 911-920.

Evans, K.M., Kuhn, S.F., Hayes, P.K., 2005. High levels of genetic diversity and low levels of genetic differentiation in North Sea Pseudo-nitzschia pungens (Bacillariophyceae) populations. J. Phycol. 41(3), 506-514.

Falkowski, P.G., Dubinsky, Z., Wyman, K., 1985. Growth-irradiance relationships in phytoplankton. Limnol. Oceanogr. 30(2), 311-321. 
Fehling, J., Davidson, K., Bolch, C.J., Bates, S.S., 2004. Growth and domoic acid production by Pseudo-nitzschia seriata (Bacillariophyceae) under phosphate and silicate limitation. J. Phycol. 40(4), 674-683.

Fehling, J., Davidson, K., Bates, S.S., 2005. Growth dynamics of non-toxic Pseudo-nitzschia delicatissima and toxic $P$. seriata (Bacillariophyceae) under simulated spring and summer photoperiods. Harmful Algae. 4(4), 763-769.

Fenchel, T., 2005. Cosmopolitan microbes and their 'cryptic' species. Aquat. Microb. Ecol. 41(1), 49-54.

Foissner, W., 2006. Biogeography and dispersal of micro-organisms: a review emphasizing protists. Acta Protozool. 45(2), 111-136.

Gallagher, J.C., 1980. Population genetics of Skeletonema costatum (Bacillariophyceae) in Narragansett Bay. J. Phycol. 16(3), 464-474.

Gallagher, J.C., 1982. Physiological variation and electrophoretic banding patterns of genetically different seasonal populations of Skeletonema costatum (Bacillariophyceae). J. Phycol. 18(1), 148-162.

Garrison, D.L., Conrad, S.M., Eilers, P.P., Waldron, E.M., 1992. Confirmation of domoic acid production by Pseudo-nitzschia australis (Bacillariophyceae) cultures. J. Phycol. 28(5), 604-607.

Garthwaite, I., Ross, K.M., Miles, C.O., Hansen, R.P., Foster, D., Towers, N.R., 1998. An immunoassay for determination of domoic acid in shellfish and sea water. Harmful Algae: Eighth International Conference on Harmful Algae, Vigo, Spain, pp.559-562.

Goldman, J.C., Dennett, M.R., 1985. Photosynthetic responses of 15 phytoplankton species to ammonium pulsing. Mar Ecol Prog Ser. 20(3), 259-264.

Hargraves, P.E., Zhang, J., Wang, R., Shimizu, Y., 1993. Growth characteristics of the diatoms Pseudo-nitzschia pungens and Pseudo-nitzschia fraudulenta exposed to ultraviolet radiation. Hydrobiologia. 269, 207-212.

Hasle, G.R., 1965. Nitzschia and Fragilariopsis species studied in the light and electron microscopes II. The group Pseudo-nitzschia. Skrift. Norske Vidensk. Akad. 18, 1-45.

Hasle, G.R., 2002. Are most of the domoic acid-producing species of the diatom genus Pseudonitzschia cosmopolites? Harmful Algae. 1(2), 137-146.

Hasle, G.R., Lundholm, N., 2005. Pseudo-nitzschia seriata f. obtusa (Bacillariophyceae) raised in rank based on morphological, phylogenetic and distributional data. Phycologia. 44(6), 608619. 
Hasle, G.R., Lange, C.B., Syvertsen, E.E., 1996. A review of Pseudo-nitzschia, with special reference to the Skagerrak, North Atlantic, and adjacent waters. Helgolander Meeresun. 50(2), 131-175.

Hillebrand, H., Sommer, U., 1996. Nitrogenous nutrition of the potentially toxic diatom Pseudonitzchia pungens f. multiseries Hasle. J. Plankton Res. 18(2), 295-301.

Holmes, M.J., Lewis, R.J., Poli, M.A., Gillespie, N.C., 1991. Strain dependent production of ciguatoxin precursors (gambiertoxins) by Gambierdiscus toxicus (Dinophyceae) in culture. 29(6), 761-775.

Jackson, A.E., Ayer, S.W., Laycock, M.V., 1992. The effect of salinity on growth and amino acid composition in the marine diatom Nitzschia pungens. Can. J. Bot. 70(11), 2198-2201.

Kaczmarska, I., Ehrman, J.M., Bates, S.S., Green, D.H., Leger, C., Harris, J., 2005. Diversity and distribution of epibiotic bacteria on Pseudo-nitzschia multiseries (Bacillariophyceae) in culture, and comparison with those on diatoms in native seawater. Harmful Algae. 4(4), 725-741.

Kotaki, Y., Koike, K., Sato, S., Ogata, T., Fukuyo, Y., Kodama, M., 1999. Confirmation of domoic acid production of Pseudo-nitzschia multiseries isolated from Ofunato Bay, Japan. Toxicon. 37(4), 677-682.

Lakeman, M. B., Cattolico, R. A., 2007. Cryptic diversity in phytoplankton cultures is revealed using a simple plating technique. J. Phycol. 43(4), 662-674.

Larsen, A., Bryant, S., 1998. Growth rate and toxicity of Prymnesium parvum and Prymnesium patelliferum (Haptophyta) in response to changes in salinity, light and temperature. Sarsia. 83(5), 409-418.

Liang, Y., Beardall, J., Heraud, P., 2006. Changes in growth, chlorophyll fluorescence and fatty acid composition with culture age in batch cultures of Phaeodactylum tricornutum and Chaetoceros muelleri (Bacillariophyceae). Bot. Mar. 49(2), 165-173.

Lomas, M.W., Glibert, P.M., 1999. Temperature regulation of nitrate uptake: a novel hypothesis about nitrate uptake and reduction in cool-water diatoms. Limnol. Oceanogr. 44(3), 556-572.

Lomas, M.W., Glibert, P.M., 2000. Comparisons of nitrate uptake, storage, and reduction in marine diatoms and flagellates. J. Phycol. 36(5), 903-913.

Losada, M., Guerrero, M.G., 1979. The photosynthetic reduction of nitrate and its regulation. In: Barber, J. (Ed.), Photosynthesis in Relation to Model Systems. Elsevier/North Holland Biomedical Press, Amsterdam, pp. 363-408.

Lundholm, N., Skov, J., Pocklington, R., Moestrup, Ø. 1994. Domoic acid, the toxic amino acid responsible for amnesic shellfish poisoning, now in Pseudo-nitzschia seriata (Bacillariophyceae) in Europe. Phycologia. 33(6), 475-478. 
Lundholm, N., Moestrup, Ø. 2002. The marine diatom Pseudo-nitzschia galaxiae sp. nov. (Bacillariophyceae): morphology and phylogenetic relationships. Phycologia. 41(6), 594-605.

Lundholm, N., Daugbjerg, N., Moestrup, Ø. 2002a. Phylogeny of the Bacillariaceae with emphasis on the genus Pseudo-nitzschia (Bacillariophyceae) based on partial LSU rDNA. Eur. J. Phycol. 37(1), 115-134.

Lundholm, N., Hasle, G.R., Fryxell, G.A., Hargraves, P.E., 2002b. Morphology, phylogeny and taxonomy of species within the Pseudo-nitzschia americana complex (Bacillariophyceae) with descriptions of two new species, Pseudo-nitzschia brasiliana and Pseudo-nitzschia linea. Phycologia. 41(5), 480-497.

Lundholm, N., Moestrup, Ø., Hasle, G.R., Hoef-Emden, K., 2003. A study of the Pseudonitzschia pseudodelicatissima/cuspidata complex (Bacillariophyceae): What is $P$. pseudodelicatissima? J. Phycol. 39(4), 797-813.

Lundholm, N., Hansen, P.J., Kotaki, Y., 2004. Effect of pH on growth and domoic acid production by potentially toxic diatoms of the genera Pseudo-nitzschia and Nitzschia. Mar. Ecol. Prog. Ser. 273(1-15.

Lundholm, N., Moestrup, Ø., Kotaki, Y., Hoef-Emden, K., Scholin, C., Miller, P., 2006. Interand intraspecific variation of the Pseudo-nitzschia delicatissima complex (Bacillariophyceae) illustrated by rRNA probes, morphological data and phylogenetic analyses. J. Phycol. 42(2), 464-481.

Maldonado, M.T., Hughes, M.P., Rue, E.L., Wells, M.L., 2002. The effect of Fe and Cu on growth and domoic acid production by Pseudo-nitzschia multiseries and Pseudo-nitzschia australis. Limnol. Oceanogr. 47(2), 515-526.

Manhart, J.R., McCourt, R.M., 1992. Molecular data and species concepts in the algae. J. Phycol. 28(6), 730-737.

Mann, D.G., 1999. Phycological Reviews 18, The species concept in diatoms. Phycologia. 38(6), 437-495.

Mann, D.G., McDonald, S.M., Bayer, M.M., Droop, S.J.M., Chepurnov, V.A., Loke, R.E., Ciobanu, A., Du Buf, J.M.H., 2004. The Sellaphora pupula species complex

(Bacillariophyceae): morphometric analysis, ultrastructure and mating data provide evidence for five new species. Phycologia. 43(4), 459-482.

Mansour, M.P., Vokman, J.K., Blackburn, S.I., 2003. The effect of growth phase on the lipid class, fatty acid and sterol composition in the marine dinoflagellate Gymnodinium sp. in batch culture. Phytochemistry 63(2), 145-153.

McCarthy, J.J., 1972. The uptake of urea by marine phytoplankton. J. Phycol. 8(3), 216-222. 
McCarthy, J.J., Taylor, W.R., Taft, J.L., 1977. Nitrogenous nutrition of plankton in Chesapeake Bay 1. Nutrient availability and phytoplankton preferences. Limnol. Oceanogr. 22(6), 996-1011.

Ogata, T., Kodama, M., Ishimaru, T., 1987. Toxin production in the dinoflagellate Protogonyaulax tamarensis. Toxicon. 25(9), 923-928.

Orsini, L., Procaccini, G., Sarno, D., Montresor, M., 2004. Multiple rDNA ITS-types within the diatom Pseudo-nitzschia delicatissima (Bacillariophyceae) and their relative abundances across a spring bloom in the Gulf of Naples. Mar. Ecol. Prog. Ser. 271, 87-98.

Pan, Y., Subba Rao, D.V., Warnock, R.E., 1991. Photosynthesis and growth of Nitzschia pungens f. multiseries Hasle, a neurotoxin producing diatom. J. Exp. Mar. Biol. Ecol. 154(1), 7796.

Pan, Y., Subba Rao, D.V., Mann, K.H., Brown, R.G., Pocklington, R., 1996a. Effects of silicate limitation on production of domoic acid, a neurotoxin, by the diatom Pseudo-nitzschia multiseries 1. Batch culture studies. 131(1-3), 225-233.

Pan, Y.L., Rao, D.V.S., Mann, K.H., 1996b. Acclimation to low light intensity in photosynthesis and growth of Pseudo-nitzschia multiseries Hasle, a neurotoxigenic diatom. J. Plankton Res. $18(8), 1427-1438$.

Pan, Y.L., Parsons, M.L., Busman, M., Moeller, P.D.R., Dortch, Q., Powell, C.L., Doucette, G.J., 2001. Pseudo-nitzschia sp cf. pseudodelicatissima - a confirmed producer of domoic acid from the northern Gulf of Mexico. Mar. Ecol. Prog. Ser. 220, 83-92.

Platt, T., Gallegos, C.L., Harrison, W.G., 1980. Photoinhibition of photosynthesis in natural assemblages of marine phytoplankton. J. Mar. Res. 38(4), 687-701.

Quilliam, M., 2003. Chemical methods for domoic acid, the amnesic shellfish poisoning (ASP) toxin. In: Cembella, A.D. (Ed.), Manual on Harmful Marine Microalgae. UNESCO Publishing, Paris, pp. 247-266.

Rivera, R.P., 1985. Chilean marine species of the genus Nitzschia Hazall, section Pseudonitzchia (Bacillariophyceae). Gayana Bot. 42(3-4), 9-38.

Rynearson, T.A., Newton, J.A., Armbrust, E.V., 2006. Spring bloom development, genetic variation, and population succession in the planktonic diatom Ditylum brightwellii. Limnol. Oceanogr. 51(3), 1249-1261.

Scheckenbach, F., Wylezich, C., Mylnikov, A.P., Weitere, M., Arndt, H., 2006. Molecular comparisons of freshwater and marine isolates of the same morphospecies of heterotrophic flagellates. Appl. Environ. Microb. 72(10), 6638-6643. 
Scholin, C., Villac, M.C., Buck, K., Krupp, J.M., Powers, D.A., Fryxell, G.A., Chavez, F., 1994. Ribosomal DNA sequences discriminate among toxic and non-toxic Pseudo-nitzschia species. Nat. Toxins. 2(152-165.

Skov, J., Lundholm, N., Moestrup, Ø., Larsen, J., 1999. Leaflet No. 185 Potentially toxic phytoplankton 4. The diatom genus Pseudo-nitzschia (Diatomophyceae/Bacillariophyceae). In: Lindley, J.A. (Ed.), ICES Identification Leaflets for Plankton. International Council for the Exploration of the Sea, Copenhagen, Denmark, pp. 1-23.

Sokal, R.R., Rohlf, F.J. 1995. Biometry. W.H. Freeman and Co., New York, 887 pp.

Stewart, J. E., 2008. Bacterial involvement in determining domoic acid levels in Pseudonitzschia multiseries cultures. Aquat. Microb. Ecol. 50, 135-144.

Stonik, I.V., Orlova, T.Y., Shevchenko, O.G., 2001. Morphology and Ecology of the Species of the Genus Pseudo-nitzschia (Bacillariophyta) from Peter the Great Bay, Sea of Japan. Russ. J. Mar. Biol. 27(6), 362-366.

Subba Rao, D.V., de Freitas, A.S.W., Quilliam, M.A., Pocklington, R., Bates, S.S., 1990. Rates of production of domoic acid, a neurotoxic amino acid in the pennate marine diatom Nitzschia pungens. In: Granéli, E., Sundström, B., Edler, L., Anderson, D.M., (Eds.) Toxic Marine Phytoplankton. Elsevier Publishing Co., pp. 413-417.

Swofford, D.L., 2002. PAUP* Phylogenetic Analysis Using Parsimony (*and other methods), 4. Sinauer Associates, Sunderland, Massachusetts.

Syrett, P.J., 1981. Nitrogen metabolism of microalgae. In: Platt, T. (Ed.), Physiological Bases of Phytoplankton Ecology Bull. No. 210. Canadian Government Publishing Center, Hull, Quebec, Canada, pp. 182-210.

Thessen, A.E., Dortch, Q., Parsons, M.L., Morrison, W., 2005. Effect of salinity on Pseudonitzschia species (Bacillariophyceae) growth and distribution. J. Phycol. 41(1), 21-29.

Villac, M.C., Roelke, D.L., Chavez, F.P., Cifuentes, L.A., Fryxell, G.A., 1993. Pseudo-nitzschia australis Frenguelli and related species from the west coast of the USA: Occurrence and domoic acid production. J. Shellfish Res. 12(2), 457-465.

Wang, R., Maranda, L., Hargraves, P.E., Shimizu, Y., 1993. Chemical variation of Nitzschia pungens as demonstrated by the cooccurrence of domoic acid and bacillariolides. In: Shimizu, Y. (Ed.), Toxic Phytoplankton Blooms in the Sea. Elsevier Science Publishers, pp. 637-641.

Ward, D. M., Weller, R., Bateson, M. M., 1990. 16S rRNA sequences reveal numerous uncultured microorganisms in a natural community. Nature 345:63-65.

Whyte, J.N.C., Ginther, N.G., Townsend, L.D., 1995. Formation of domoic acid and fatty acids in Pseudo-nitzschia pungens f. multiseries with scale of culture. J. Appl. Phycol. 7(2), 199-205. 
Wohlgeschaffen, G.D., Rao, D.V.S., Mann, K.H., 1992. Vat incubator with immersion core illumination - a new, inexpensive setup for mass phytoplankton culture. J. Appl. Phycol. 4(1), 25-29.

Wood, A.M., Leatham, T., 1992. The species concept in phytoplankton ecology. J. Phycol. 28(6), 723-729.

Wood, A.M., Everroad, R.C., Wingard, L.M., 2005. Measuring growth rates in algal cultures. In: Andersen, R.A. (Ed.), Algal Culturing Techniques. Elsevier Academic Press, New York, pp. 269-286. 
Table 1: Cultures of Pseudo-nitzschia spp. used in the present study.

\begin{tabular}{|c|c|c|c|c|c|c|c|}
\hline \multirow{2}{*}{ Clone } & \multirow{2}{*}{ Species } & \multicolumn{2}{|c|}{ GenBank Accession \# } & \multicolumn{4}{|c|}{ Collection Site Information $^{\mathrm{a}}$} \\
\hline & & ITS & LSU & Station & Date & Temp $\left({ }^{\circ} \mathrm{C}\right.$ & Salinity \\
\hline Pn-1 & $\begin{array}{c}\text { Pseudo-nitzschia } \\
\text { multiseries }\end{array}$ & DQ445651 & DQ445638 & Choptank River & 11/18/2002 & 11 & 17 \\
\hline Pn-2 & $\begin{array}{c}\text { Pseudo-nitzschia } \\
\text { calliantha }\end{array}$ & DQ445652 & DQ445639 & Choptank River & $4 / 28 / 2003$ & 15 & 9 \\
\hline Pn-3 & $\begin{array}{c}\text { Pseudo-nitzschia } \\
\text { calliantha }\end{array}$ & DQ445653 & DQ445640 & Choptank River & $4 / 14 / 2003$ & 10 & 11 \\
\hline Pn-4 & $\begin{array}{c}\text { Pseudo-nitzschia } \\
\text { calliantha }\end{array}$ & DQ445654 & DQ445641 & Chesapeake Bay & $10 / 3 / 2003$ & 21 & 17 \\
\hline Pn-5 & $?$ & & & Chesapeake Bay & $10 / 3 / 2003$ & 21 & 17 \\
\hline Pn-6 & $\begin{array}{l}\text { Pseudo-nitzschia } \\
\text { calliantha }\end{array}$ & DQ445655 & DQ445642 & Chesapeake Bay & $10 / 4 / 2003$ & 20 & 12 \\
\hline Pn-7 & $\begin{array}{c}\text { Pseudo-nitzschia } \\
\text { calliantha }\end{array}$ & DQ445656 & DQ445643 & Patuxent River & $10 / 13 / 2003$ & 20 & 11 \\
\hline Pn-8 & $\begin{array}{c}\text { Pseudo-nitzschia } \\
\text { calliantha }\end{array}$ & DQ445657 & DQ445644 & Choptank River & $10 / 20 / 2003$ & 17 & 10 \\
\hline Pn-9 & $\begin{array}{l}\text { Pseudo-nitzschia } \\
\text { fraudulenta }\end{array}$ & DQ445659 & DQ445645 & Assateague Island & $3 / 28 / 2004$ & 6 & 32 \\
\hline Pn-10 & $\begin{array}{l}\text { Pseudo-nitzschia } \\
\text { fraudulenta }\end{array}$ & DQ445660 & DQ445646 & Assateague Island & $3 / 28 / 2004$ & 6 & 32 \\
\hline Pn-11 & $\begin{array}{l}\text { Pseudo-nitzschia } \\
\text { fraudulenta }\end{array}$ & DQ445661 & DQ445647 & Assateague Island & $3 / 28 / 2004$ & 6 & 32 \\
\hline Pn-12 & $\begin{array}{l}\text { Pseudo-nitzschia } \\
\text { fraudulenta }\end{array}$ & DQ445662 & DQ445648 & Assateague Island & $3 / 28 / 2004$ & 6 & 32 \\
\hline Pn-13 & $\begin{array}{c}\text { Pseudo-nitzschia } \\
\text { calliantha }\end{array}$ & DQ445658 & DQ445649 & Choptank River & $5 / 17 / 2004$ & 23 & 9 \\
\hline Pn-14 & $\begin{array}{l}\text { Pseudo-nitzschia } \\
\text { calliantha }\end{array}$ & & & Kiptopeke Virginia & $11 / 11 / 2004$ & 14 & 30 \\
\hline Pn-15 & $\begin{array}{l}\text { Pseudo-nitzschia } \\
\text { fraudulenta }\end{array}$ & DQ445663 & DQ445650 & Asilomar California & $10 / 7 / 2005$ & 11 & 32 \\
\hline CLN47 & $\begin{array}{c}\text { Pseudo-nitzschia } \\
\text { multiseries }\end{array}$ & & & CL147 X CL191 & $6 / 16 / 2005$ & & \\
\hline Pn-16 & $\begin{array}{l}\text { Pseudo-nitzschia } \\
\text { calliantha }\end{array}$ & EF621757 & EF621754 & Tangier Sound & $11 / 14 / 2006$ & 13 & 15 \\
\hline Pn-17 & $\begin{array}{c}\text { Pseudo-nitzschia } \\
\text { calliantha }\end{array}$ & EF621758 & EF621755 & Tangier Sound & $11 / 14 / 2006$ & 13 & 15 \\
\hline Pn-18 & $\begin{array}{c}\text { Pseudo-nitzschia } \\
\text { calliantha }\end{array}$ & EF621759 & EF621756 & Tangier Sound & $11 / 14 / 2006$ & 13 & 15 \\
\hline
\end{tabular}

${ }^{\mathrm{a}}$ Collection site information column contains data on water samples from which cultures were isolated.

${ }^{\mathrm{b}}$ Strain CLN47 was isolated after sexual reproduction between strains CL147 and CL191. 
Table 2: Limit of quantitation and limit of detection for ELISA method used to analyze data presented in Figs. 3 and 4.

Particulate DA for Panel A and Panel C were obtained via HPLC, thus no LOD is presented.

\begin{tabular}{cccccc}
\hline \multirow{2}{*}{ Panel } & \multirow{2}{*}{ Number } & \multicolumn{2}{c}{ particulate } & \multicolumn{2}{c}{ dissolved } \\
& LOQ & LOD & LOQ & LOD \\
\hline A & 1 & 375 & & 345 & 115 \\
B & 1 & 163.2 & 54.4 & 1020 & 340 \\
& 2 & 28.8 & 9.6 & 1020 & 340 \\
& 3 & 792 & 264 & 1020 & 340 \\
& 4 & 792 & 264 & 396 & 132 \\
C & 1 & 375 & & 420 & 140 \\
& 2 & 375 & & 1020 & 340 \\
& 3 & 375 & & 1165 & 388.3 \\
D & 1 & 111.2 & 37 & 1165 & 388.3 \\
& 2 & 28.4 & 9.47 & 420 & 140 \\
E & 1 & 55.2 & 18.4 & 345 & 115 \\
& 2 & 44.8 & 14.9 & 345 & 115 \\
& 3 & 55.2 & 18.4 & 1020 & 340 \\
& 4 & 28.8 & 9.6 & 1020 & 340 \\
F & 1 & 111.2 & 37 & 420 & 140 \\
& 2 & 34 & 11.3 & 420 & 140 \\
\hline
\end{tabular}


Table 3: Replicates (n) for experiments testing growth and toxin production in cultures grown on different nitrogen sources. Data are in Figures 5, 6 and 7.

\begin{tabular}{ccccccccc}
\hline \multirow{2}{*}{ Strain } & \multirow{2}{*}{ Species } & \multicolumn{3}{c}{ toxin } & & \multicolumn{3}{c}{ growth } \\
\cline { 7 - 9 } \cline { 6 - 8 } & & $\mathrm{NO}_{3}{ }^{-}$ & $\mathrm{NH}_{4}{ }^{+}$ & urea & & $\mathrm{NO}_{3}^{-}$ & $\mathrm{NH}_{4}{ }^{+}$ & urea \\
\hline Pn-1 & P. multiseries & $5^{\mathrm{a}} / 5^{\mathrm{b}}$ & $5 / 5$ & $5 / 5$ & & 5 & 5 & 5 \\
Pn-3 & P. calliantha & & & & 4 & 5 & 5 \\
Pn-8 & P. calliantha & $5 / 5$ & $5 / 5$ & $5 / 5$ & & & \\
Pn-9 & P. fraudulenta & $5 / 5$ & $3 / 5$ & $4 / 4$ & 5 & 5 & 5 \\
Pn-10 & P. fraudulenta & & & & 5 & 5 & 4 \\
Pn-11 & P. fraudulenta & & & & 5 & 5 & 5 \\
Pn-12 & P. fraudulenta & $5 / 5$ & $5 / 4$ & $5 / 5$ & 5 & 5 & 5 \\
Pn-13 & P. calliantha & & & & 5 & 5 & 5 \\
Pn-15 & P. fraudulenta & & & & 5 & 5 & 5 \\
CLN47 & P. multiseries & $5 / 5$ & $5 / 5$ & $5 / 5$ & 5 & 5 & 5 \\
\hline
\end{tabular}

${ }^{a}$ replicates for the particulate fraction

${ }^{b}$ replicates for the dissolved fraction 


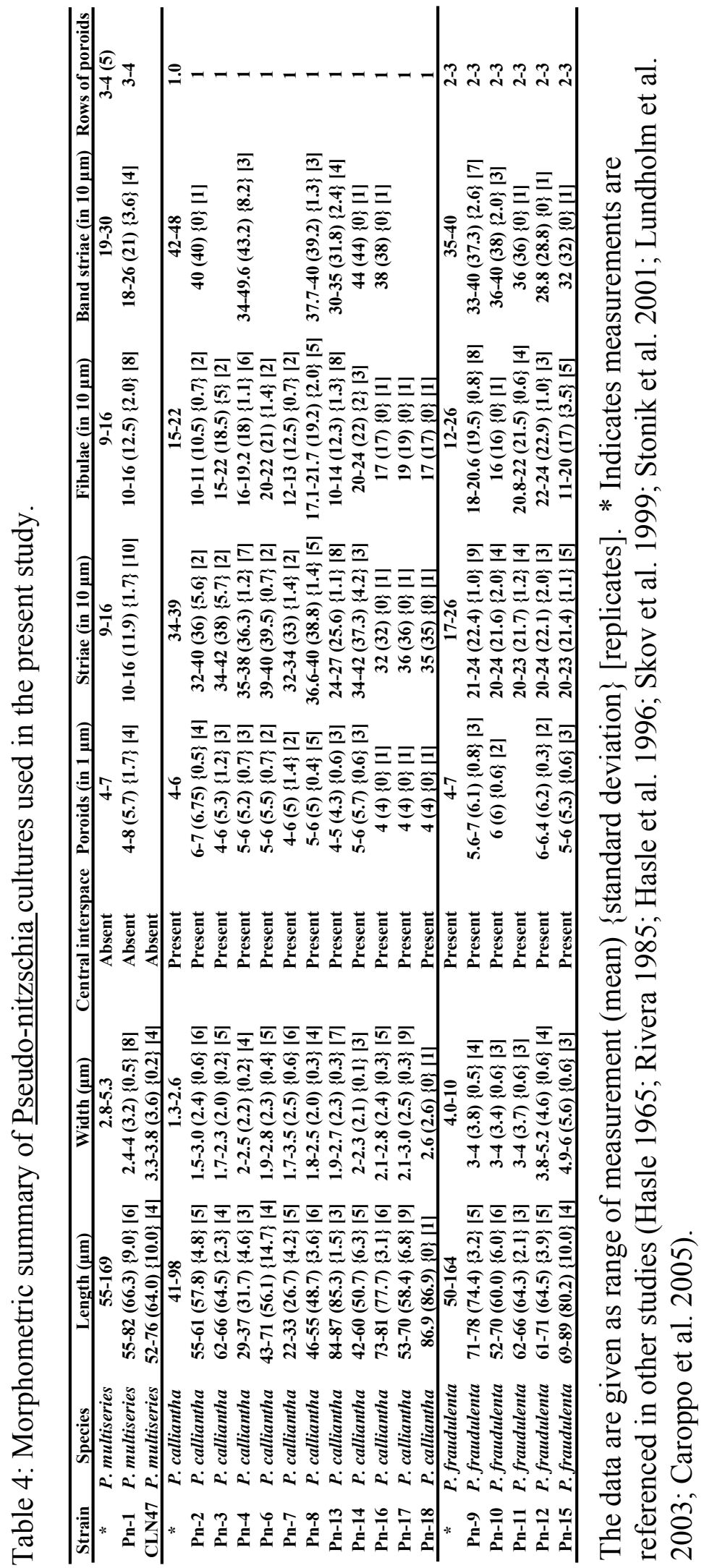




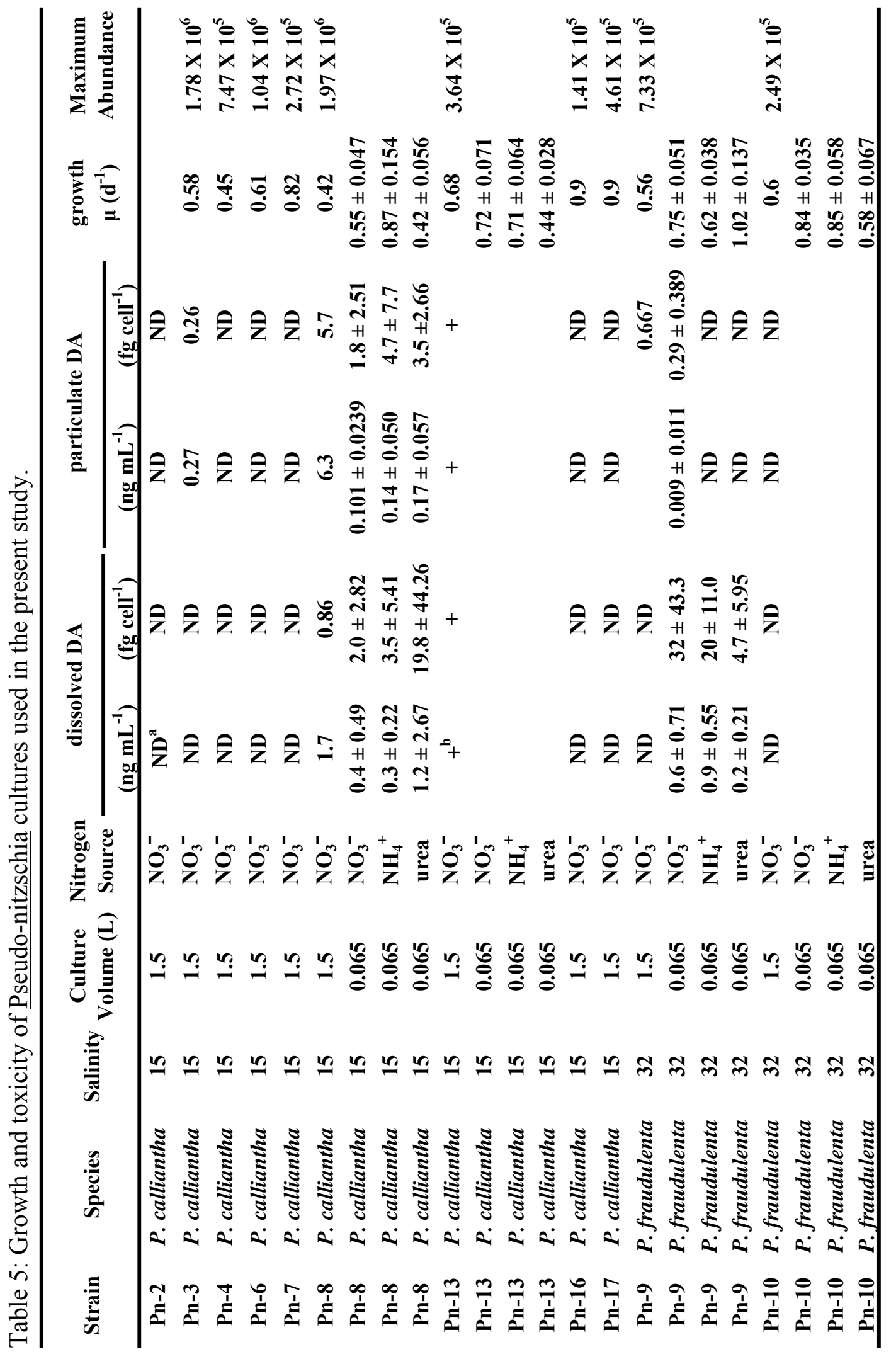




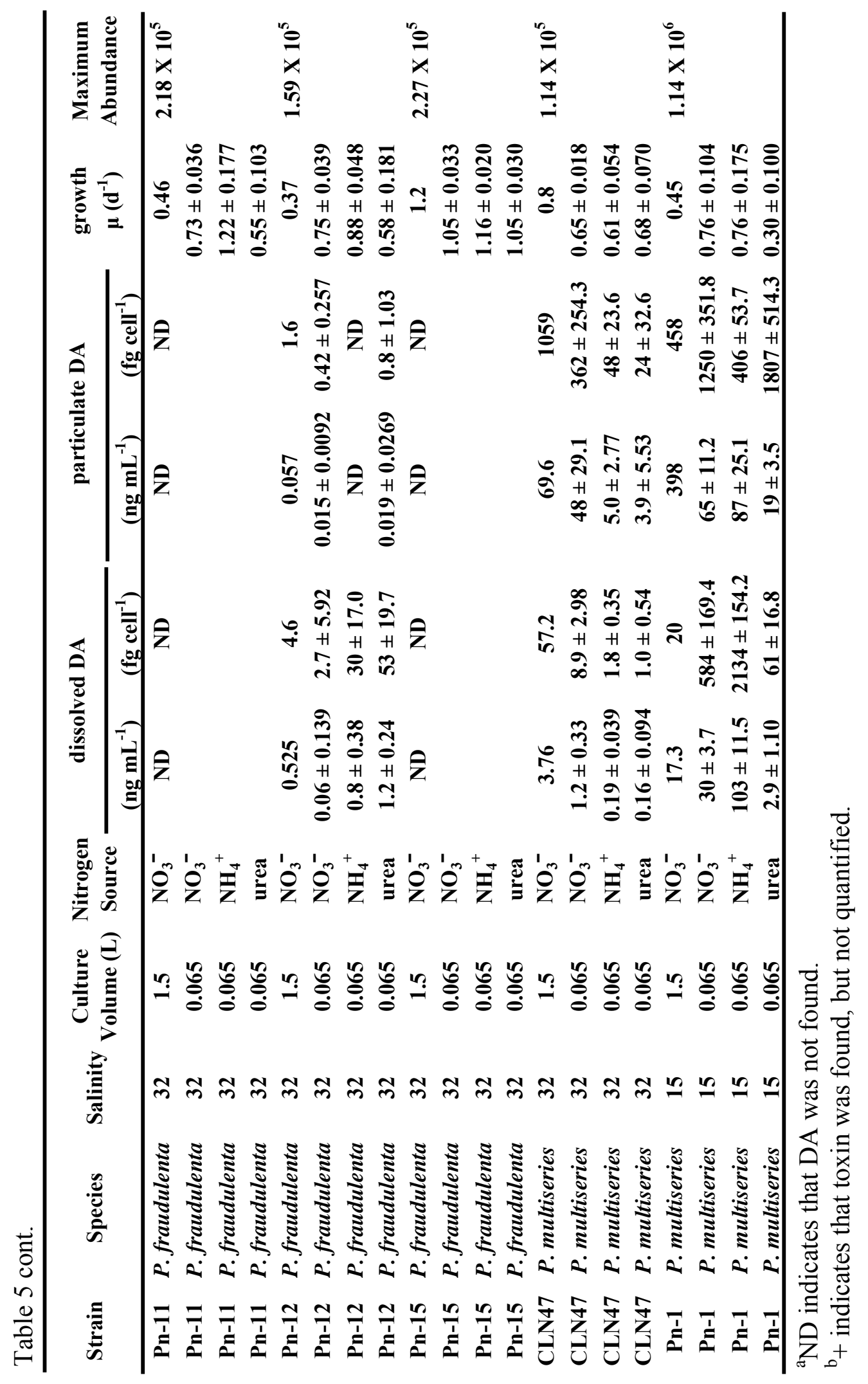


Table 6: Nested ANOVA tables for growth and toxicity experiments using different nitrogen sources.

\begin{tabular}{|c|c|c|c|c|c|}
\hline Growth (Fig. 5) & df & SS & MS & $\mathbf{F}$ & $\mathbf{P}$ \\
\hline nitrogen & 2 & 1.22 & 0.611 & 77.1 & $<0.001$ \\
\hline species nested in nitrogen & 6 & 1.79 & 0.298 & 37.6 & $<0.001$ \\
\hline strain nested in species nested in nitrogen & 18 & 3.39 & 0.188 & 23.7 & $<0.001$ \\
\hline replicate cultures & 106 & 0.84 & 0.008 & & \\
\hline Dissolved DA cell ${ }^{-1}$ (Fig. 7) & df & SS & MS & $\mathbf{F}$ & $\mathbf{P}$ \\
\hline nitrogen & 2 & 1751435 & 875717 & 216.7 & $<0.001$ \\
\hline species nested in nitrogen & 6 & 6875495 & 1145916 & 283.5 & $<0.001$ \\
\hline strain nested in species nested in nitrogen & 6 & 12139455 & 2023243 & 500.6 & $<0.001$ \\
\hline replicate cultures & 56 & 226342 & 4042 & & \\
\hline Dissolved DA $\mathrm{mL}^{-1}$ (Fig. 6) & df & SS & MS & $\mathbf{F}$ & $\mathbf{P}$ \\
\hline nitrogen & 2 & 4038 & 2019 & 180.5 & $<0.001$ \\
\hline species nested in nitrogen & 6 & 16393 & 2732 & 244.3 & $<0.001$ \\
\hline strain nested in species nested in nitrogen & 6 & 28338 & 4723 & 422.3 & $<0.001$ \\
\hline replicate cultures & 56 & 626 & 11 & & \\
\hline Particulate DA cell ${ }^{-1}$ (Fig. 7) & df & SS & MS & $\mathbf{F}$ & $\mathbf{P}$ \\
\hline nitrogen & 2 & 935125 & 467562 & 13.8 & $<0.001$ \\
\hline species nested in nitrogen & 6 & 8974923 & 1495821 & 44.3 & $<0.001$ \\
\hline strain nested in species nested in nitrogen & 6 & 10097263 & 1682877 & 49.8 & $<0.001$ \\
\hline replicate cultures & 58 & 1958029 & 33759 & & \\
\hline Particulate DA mL ${ }^{-1}$ (Fig. 6) & df & SS & MS & $\mathbf{F}$ & $\mathbf{P}$ \\
\hline nitrogen & 2 & 3522 & 1761 & 15.5 & $<0.001$ \\
\hline species nested in nitrogen & 6 & 31698 & 5283 & 46.5 & $<0.001$ \\
\hline strain nested in species nested in nitrogen & 6 & 18149 & 3025 & 26.6 & $<0.001$ \\
\hline replicate cultures & 58 & 6595 & 114 & & \\
\hline Total DA cell ${ }^{-1}$ (Fig. 7) & df & SS & MS & $\mathbf{F}$ & $\mathbf{P}$ \\
\hline nitrogen & 2 & 136266 & 68133 & 1.7 & 0.200 \\
\hline species nested in nitrogen & 6 & 21394034 & 3565672 & 87.8 & $<0.001$ \\
\hline strain nested in species nested in nitrogen & 6 & 28286001 & 4714333 & 116.1 & $<0.001$ \\
\hline replicate cultures & 60 & 2436325 & 40605 & & \\
\hline Total DA mL ${ }^{-1}$ (Fig. 6) & df & SS & MS & $\mathbf{F}$ & $\mathbf{P}$ \\
\hline nitrogen & 2 & 11648 & 5824 & 67.3 & $<0.001$ \\
\hline species nested in nitrogen & 6 & 85654 & 14276 & 165.0 & $<0.001$ \\
\hline strain nested in species nested in nitrogen & 6 & 90050 & 15008 & 173.5 & $<0.001$ \\
\hline replicate cultures & 56 & 4845 & 87 & & \\
\hline
\end{tabular}




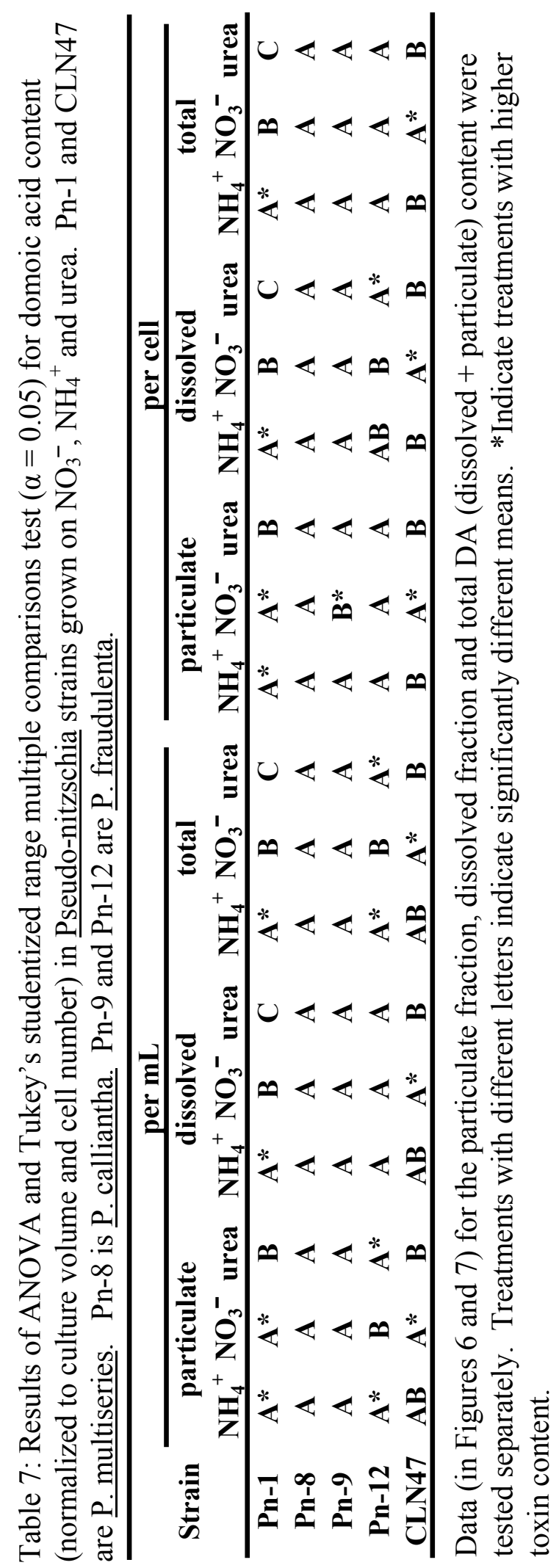




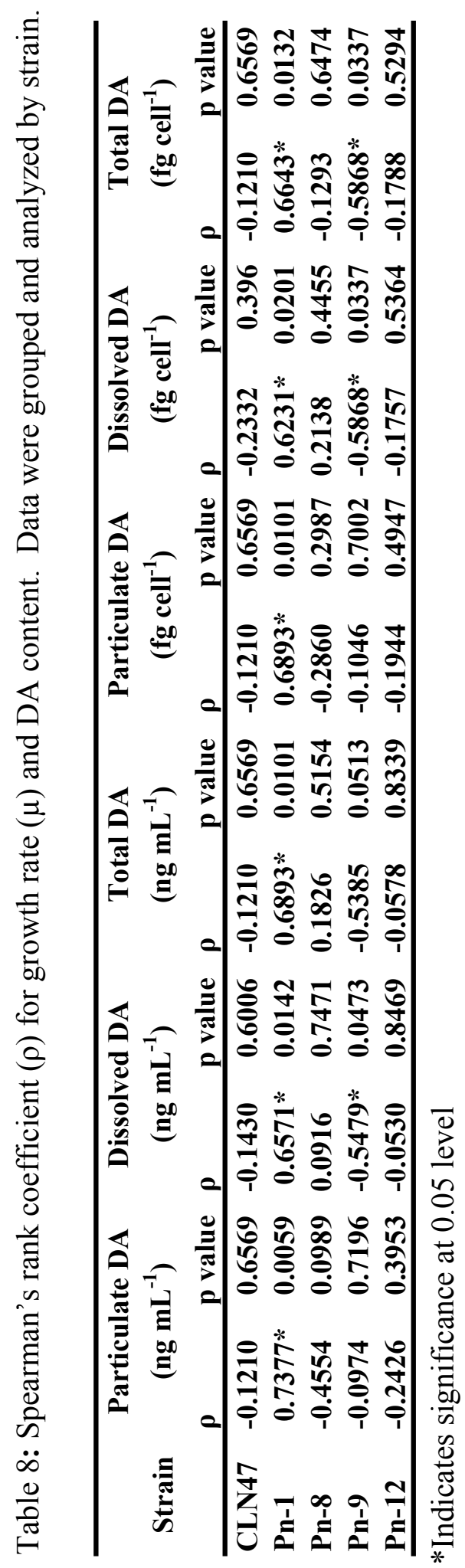




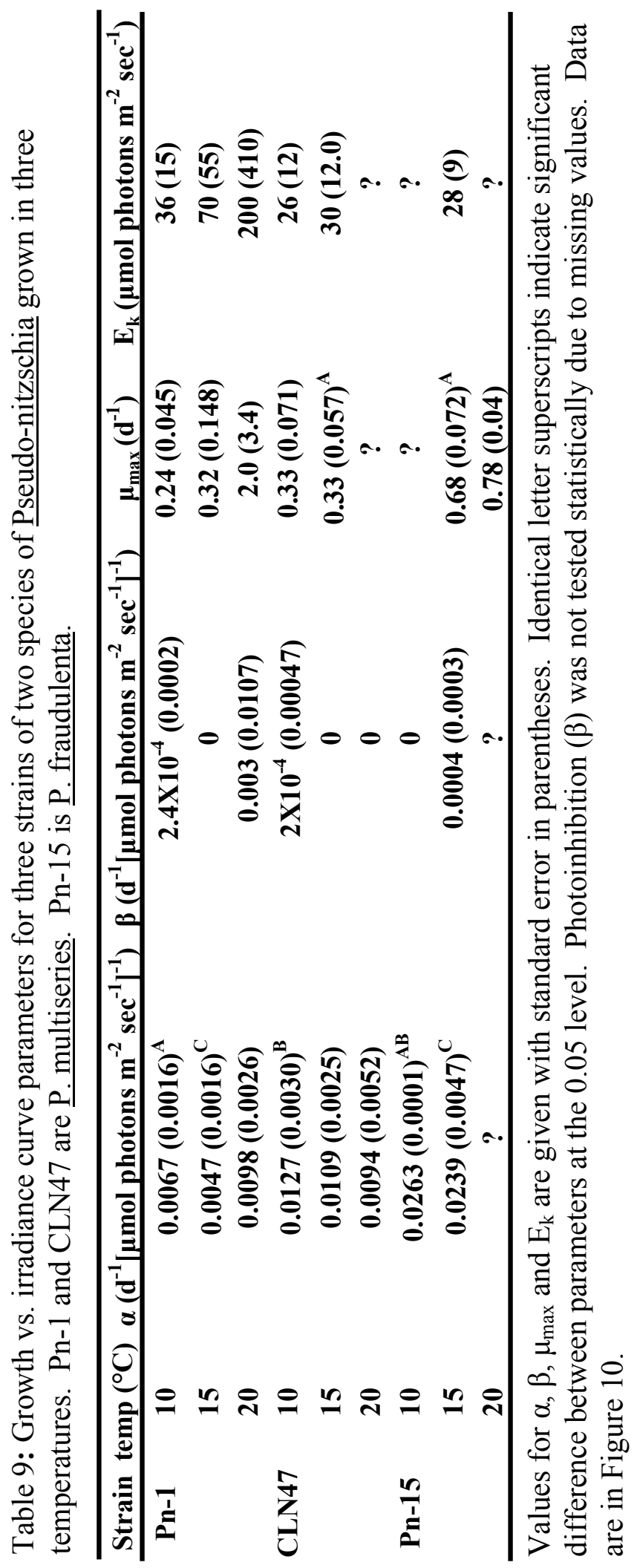


Table 10: Age of cultures in years at the time of experimentation.

\begin{tabular}{ccccc}
\hline \multirow{2}{*}{ Strain } & Species & \multicolumn{3}{c}{ Culture Age (year) } \\
\cline { 3 - 5 } & & Toxin $^{\mathrm{a}}$ & Nitrogen $^{\mathrm{b}}$ Irradiance $^{\mathrm{c}}$ \\
\hline Pn-1 & P. multiseries & 1.5 & 2.5 & 2.2 \\
Pn-3 & P. calliantha & 1 & & \\
Pn-4 & P. calliantha & 0.3 & & \\
Pn-6 & P. calliantha & 0.3 & & \\
Pn-7 & P. calliantha & 0.5 & & \\
Pn-8 & P. calliantha & 0.5 & 1.5 \\
Pn-9 & P. fraudulenta & 0.25 & 1.2 \\
Pn-10 & P. fraudulenta & 0.75 & 1.2 & \\
Pn-11 & P. fraudulenta & 0.75 & 1.2 \\
Pn-12 & P. fraudulenta & 0.75 & 1.3 \\
Pn-13 & P. calliantha & 0.6 & 1 & \\
Pn-15 & P. fraudulenta & 0.25 & 0.2 \\
CLN47 & P. multiseries & 1.2 & 1.3 \\
Pn-16 & P. calliantha & 0.2 & \\
Pn-17 & P.calliantha & 0.2 &
\end{tabular}


Figure 1: TEM micrographs of digested frustules of Pseudo-nitzschia cultures. A, B and C (scale bar $=1 \mu \mathrm{m}$ ) show arrangement of poroids. D, E and $\mathrm{F}$ (scale bar $=5 \mu \mathrm{m}$ ) show presence or absence of central interspace (arrows) and length of transapical axis. A and $\mathrm{F}$ are $\underline{\mathrm{P} \text {. fraudulenta }}$ $(\mathrm{Pn}-12), \mathrm{B}$ and $\mathrm{E}$ are $\underline{\mathrm{P} \text {. calliantha }}(\mathrm{Pn}-13)$ and $\mathrm{C}$ and $\mathrm{D}$ are $\underline{\mathrm{P} \text {. multiseries }}(\mathrm{Pn}-1)$.

Figure 2: Parsimony tree inferred for the D1-D3 variable region of LSU (A; 720 positions included) and for the ITS1-5.8S-ITS2 region (B; approx. 990 positions included) from Chesapeake Bay isolates of Pseudo-nitzschia (in bold) and sequence data available on GenBank. Analysis was performed using heuristic searches (25X random addition of sequences) with TBR (tree bisection and reconnection) branch swapping. Gaps were treated as a fifth character state in figure $2 \mathrm{~A}$, and the approximate number of character changes are shown on branches. Each species includes culture identification, location and GenBank accession number.

Figure 3: Abundance (open squares) and DA concentration normalized to culture volume (diamonds) over time in six Pseudo-nitzschia strains of three species grown in silicate-limited medium with $\mathrm{NO}_{3}{ }^{-}$as a nitrogen source. DA concentrations represent the sum of particulate and dissolved fractions. Open diamonds represent semi-quantitative data $(<\mathrm{LOQ}$, but $>$ LOD). Closed diamonds represent quantitative values ( $>$ LOQ). Numbers shown within diamonds indicate LOD and LOQ for each sample in $\mathrm{pg} \mathrm{mL}^{-1}$ which can be found in Table 2. Zero values

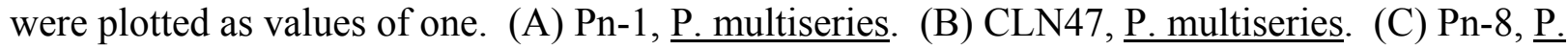
calliantha. (D) Pn-3, P. calliantha. (E) Pn-12, $\underline{\text {. fraudulenta. (F) Pn-9, P. fraudulenta. }}$

Figure 4: Abundance (open squares) and DA concentration normalized to cell number (diamonds) over time in six Pseudo-nitzschia strains of three species. DA concentrations represent the sum of particulate and dissolved fractions. Closed diamonds represent quantitative values (definitions as in Fig. 3). LOD and LOQ for each sample are given in Table 2. Zero values were plotted as values of 1 . (A) Pn-1, P. multiseries. (B) CLN47, P. multiseries. Open diamonds indicate samples where dissolved fraction was below LOQ. (C) Pn-8, P. calliantha. (D) Pn-3, P. calliantha. (E) Pn-12, P. fraudulenta. (F) Pn-9, P. fraudulenta.

Figure 5: Specific growth rates $(\mu)$ for strains of Pseudo-nitzschia grown on $\mathrm{NO}_{3}{ }^{-}, \mathrm{NH}_{4}{ }^{+}$and urea. Error bars represent one SD. Means with identical letters above bars are not significantly different at 0.05 using Tukey's studentized range test for each strain. Strain designations are given along the $\mathrm{x}$ axis and species names are given at the top of the figure. Replication is shown in Table 3.

Figure 6: DA content $\left(\mathrm{ng} \mathrm{mL}^{-1}\right)$ one week after fluorescence peak in strains of Pseudo-nitzschia grown on $\mathrm{NO}_{3}{ }^{-}, \mathrm{NH}_{4}{ }^{+}$and urea in silicate-limited media. Filled bars show particulate DA and open bars show dissolved DA. Error bars represent one SD. Letters showing significant difference are in Table 7. Replication is shown in Table 3. Note the differences in scale. (A) Pn-

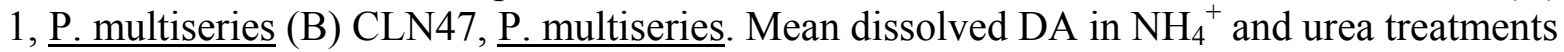
contain semi-quantitative data ( $<$ LOQ, but $>$ LOD). (C) Pn-8, P. calliantha. Mean dissolved DA in the $\mathrm{NH}_{4}{ }^{+}$treatment contains semi-quantitative data. (D) Pn-12, $\mathrm{P}$. fraudulenta. Mean dissolved DA in the $\mathrm{NH}_{4}{ }^{+}$and $\mathrm{NO}_{3}{ }^{-}$treatments and particulate $\mathrm{DA}$ in the $\mathrm{NO}_{3}{ }^{-}$and urea treatments contain semi-quantitative data. (E) Pn-9, P. fraudulenta. Mean dissolved DA in all treatments and particulate $\mathrm{DA}$ in the $\mathrm{NO}_{3}{ }^{-}$treatment contain semi-quantitative data. 
Figure 7: DA content (fg cell ${ }^{-1}$ ) one week after fluorescence peak for strains of Pseudo-nitzschia grown on $\mathrm{NO}_{3}{ }^{-}, \mathrm{NH}_{4}{ }^{+}$and urea in silicate limited media. Filled bars show particulate DA and open bars show dissolved DA. Error bars represent one SD. Letters showing significant difference are in Table 7. Replication is shown in Table 3. Note the difference in scale. (A) Pn1, $\mathrm{P}$. multiseries (B) CLN47, P. multiseries. Mean dissolved DA in $\mathrm{NH}_{4}{ }^{+}$and urea treatments contain semi-quantitative data $(<\mathrm{LOQ}$, but $>$ LOD). (C) Pn -8 , P. calliantha. Mean dissolved DA in the $\mathrm{NH}_{4}{ }^{+}$treatment contains semi-quantitative data. (D) Pn-12, P. fraudulenta. Mean dissolved DA in the $\mathrm{NH}_{4}{ }^{+}$and $\mathrm{NO}_{3}{ }^{-}$treatments and particulate $\mathrm{DA}$ in the $\mathrm{NO}_{3}{ }^{-}$and urea treatments contain semi-quantitative data. (E) Pn-9, P. fraudulenta. Mean dissolved DA in all treatments and particulate $\mathrm{DA}$ in the $\mathrm{NO}_{3}{ }^{-}$treatment contain semi-quantitative data.

Figure 8: Growth rates in exponential phase (shaded bars) and total DA content (ng mL $\mathrm{mL}^{-1}$; open bars) one week after fluorescence peak in strains of Pseudo-nitzschia grown in batch culture on $\mathrm{NO}_{3}{ }^{-}, \mathrm{NH}_{4}{ }^{+}$and urea in silicate-limited media. Error bars represent one SD. Spearman's correlation coefficients are in Table 8. Replication is shown in Table 3. Note the difference in scale. (A) Pn-1, P. multiseries (B) CLN47, P. multiseries. (C) Pn-8, P. calliantha. (D) Pn-12, P. fraudulenta. (E) Pn-9, P. fraudulenta.

Figure 9: Growth rates in exponential phase (shaded bars) and total DA content (fg cell ${ }^{-1}$; open bars) one week after fluorescence peak in strains of Pseudo-nitzschia grown in batch culture on $\mathrm{NO}_{3}{ }^{-}, \mathrm{NH}_{4}{ }^{+}$and urea in silicate-limited media. Error bars represent one SD. Spearman's correlation coefficients are in Table 8. Replication is shown in Table 3. Note the difference in scale. (A) Pn-1, P. multiseries (B) CLN47, P. multiseries. (C) Pn-8, P. calliantha. (D) Pn-12, $\underline{\text {. }}$ fraudulenta. (E) Pn-9, P. fraudulenta.

Figure 10: Growth vs. irradiance curves for three strains of two species of Pseudo-nitzschia at three temperatures $\left(10^{\circ}, 15^{\circ}, 20^{\circ} \mathrm{C}\right)$ in nutrient replete medium. (A) Pn-1, $\underline{\text { P. multiseries (B) }}$ CLN47, P. multiseries (C) Pn-15, P. fraudulenta. Photosynthetic parameters derived from curves are summarized in Table 9. 
Fig. 1

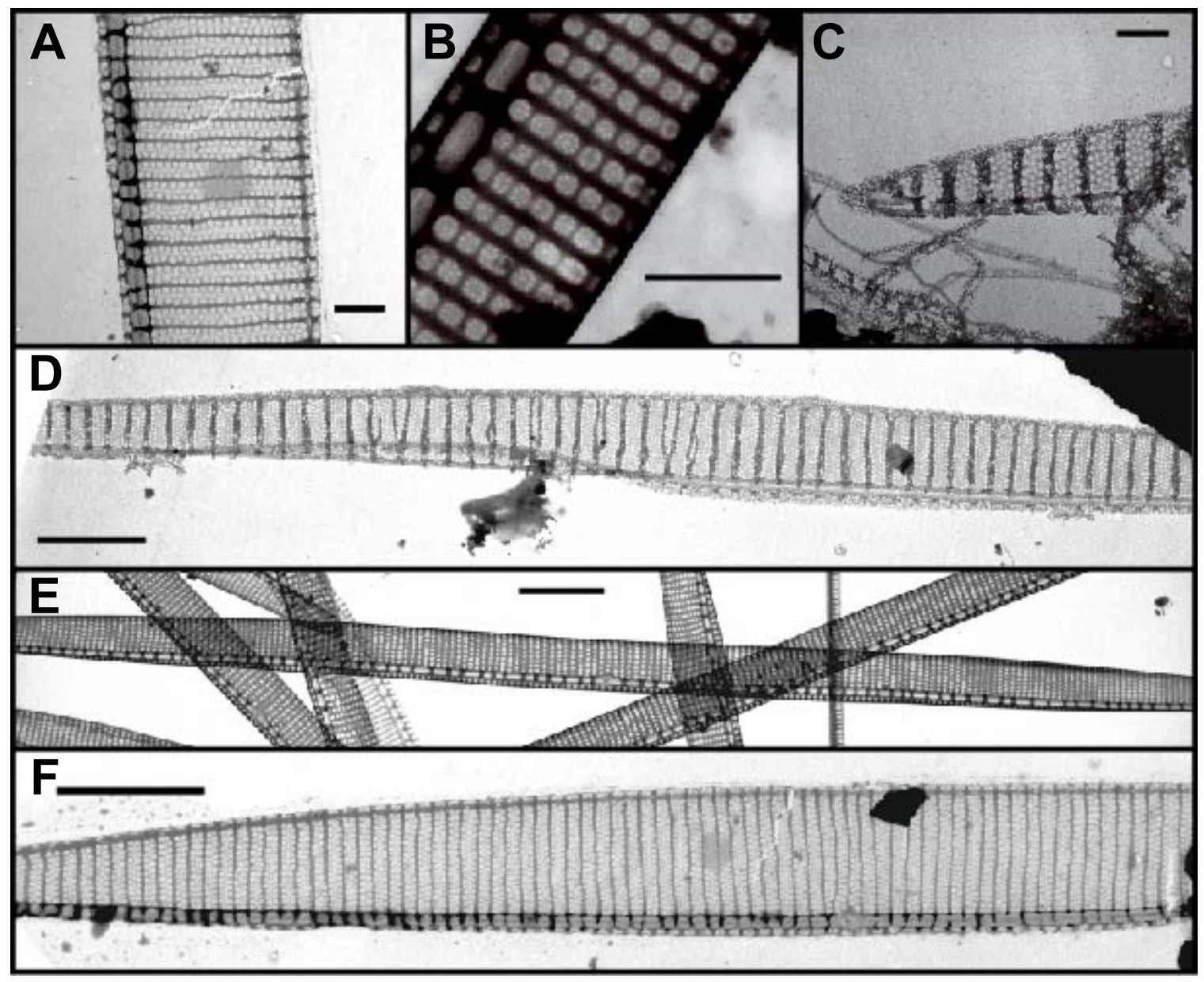


Fig. 2A

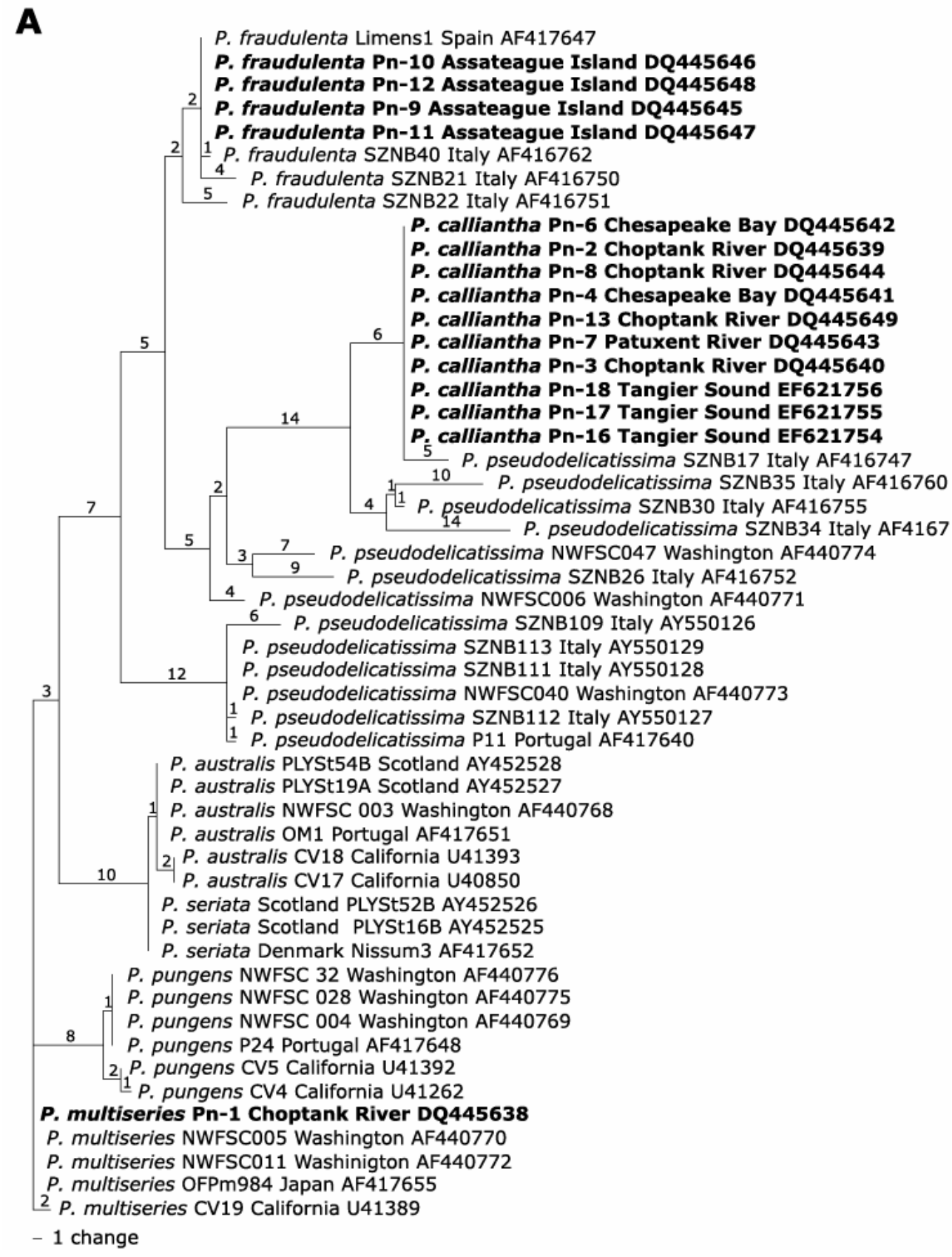


Fig. 2B

\section{B}

P. multiseries OFPm984 Japan AF417655
P. multiseries Pn-1 Choptank River DQ445651
P. multiseries mu3 California AY257844

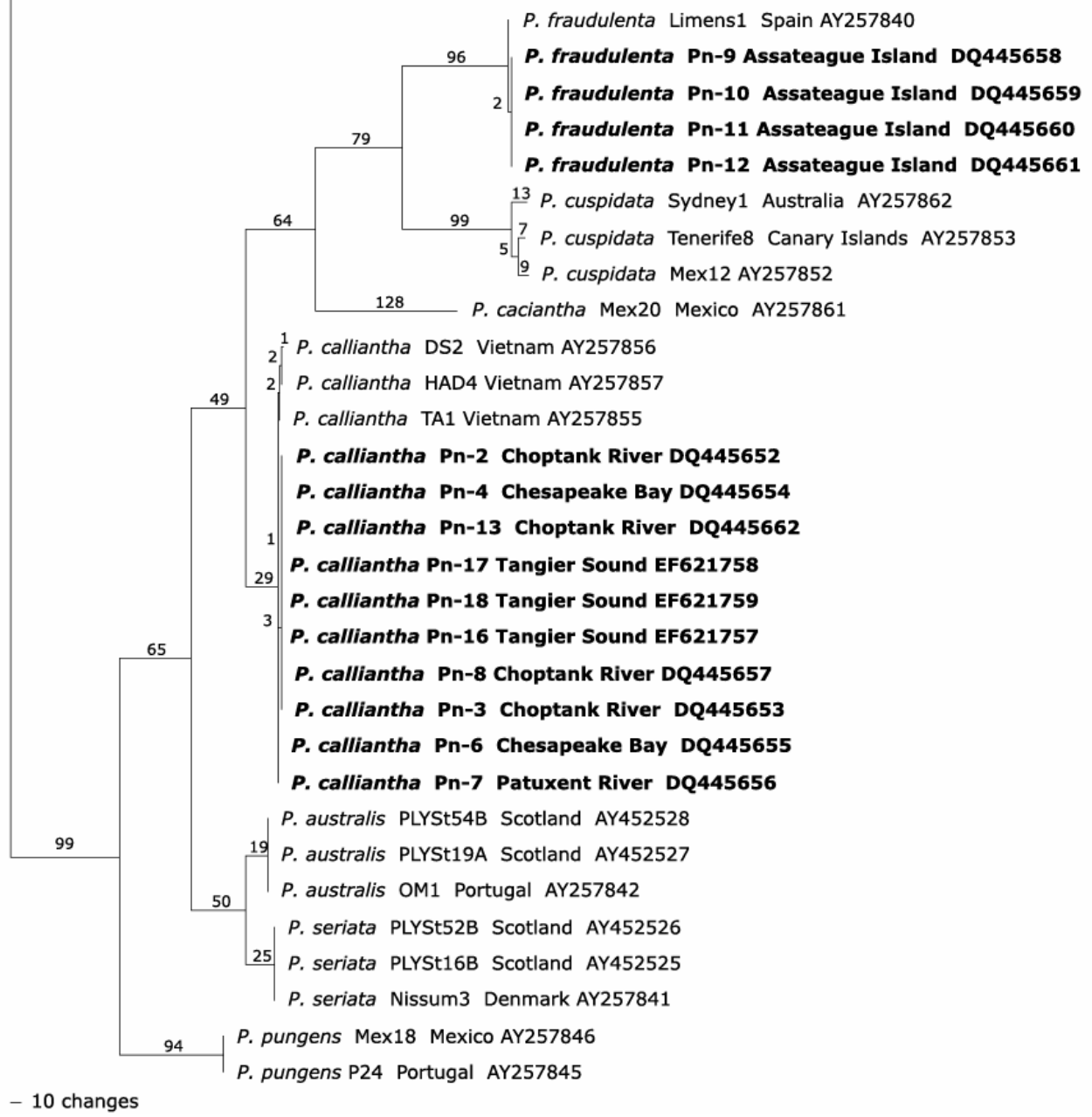


Fig. 3

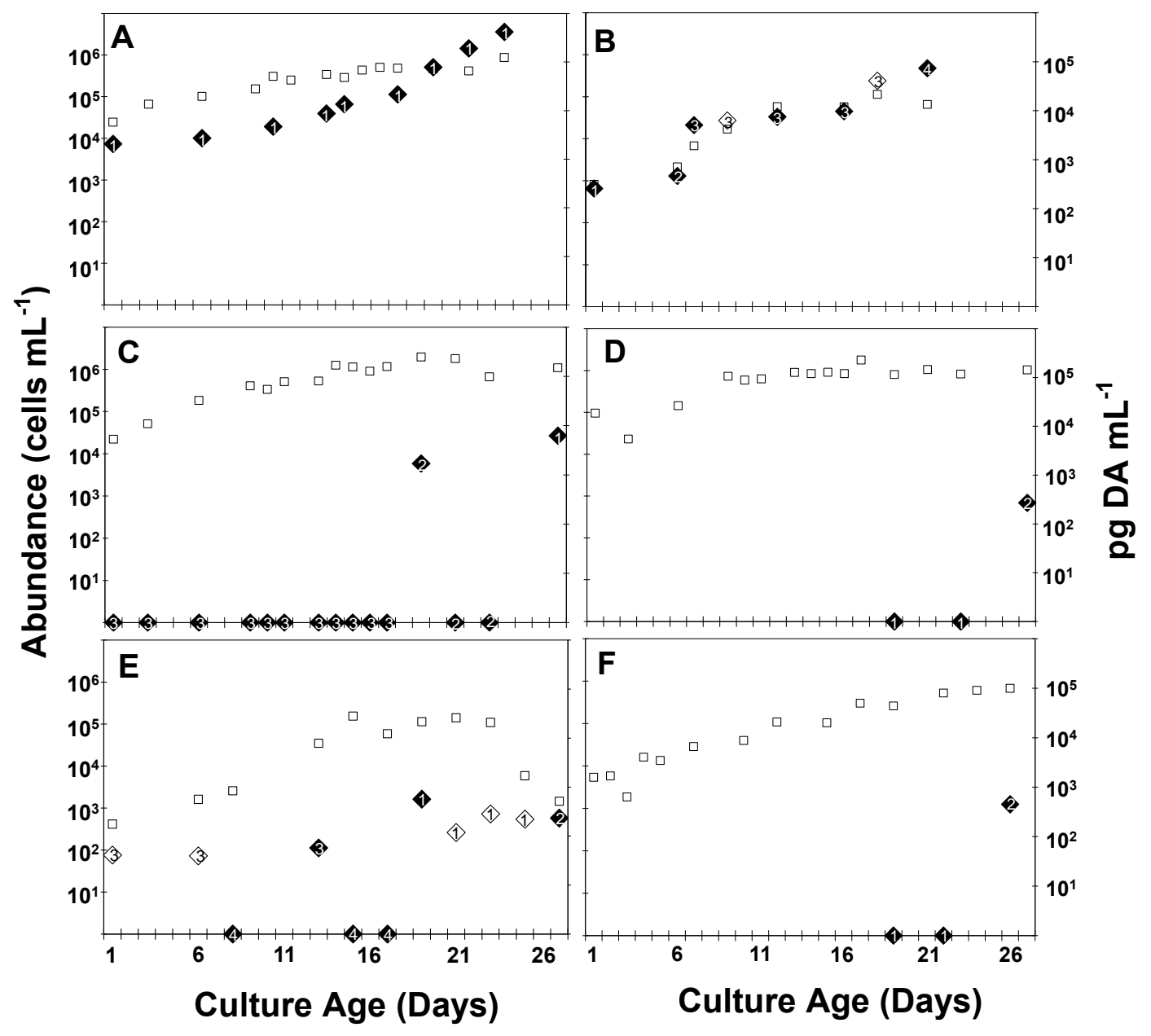


Fig. 4

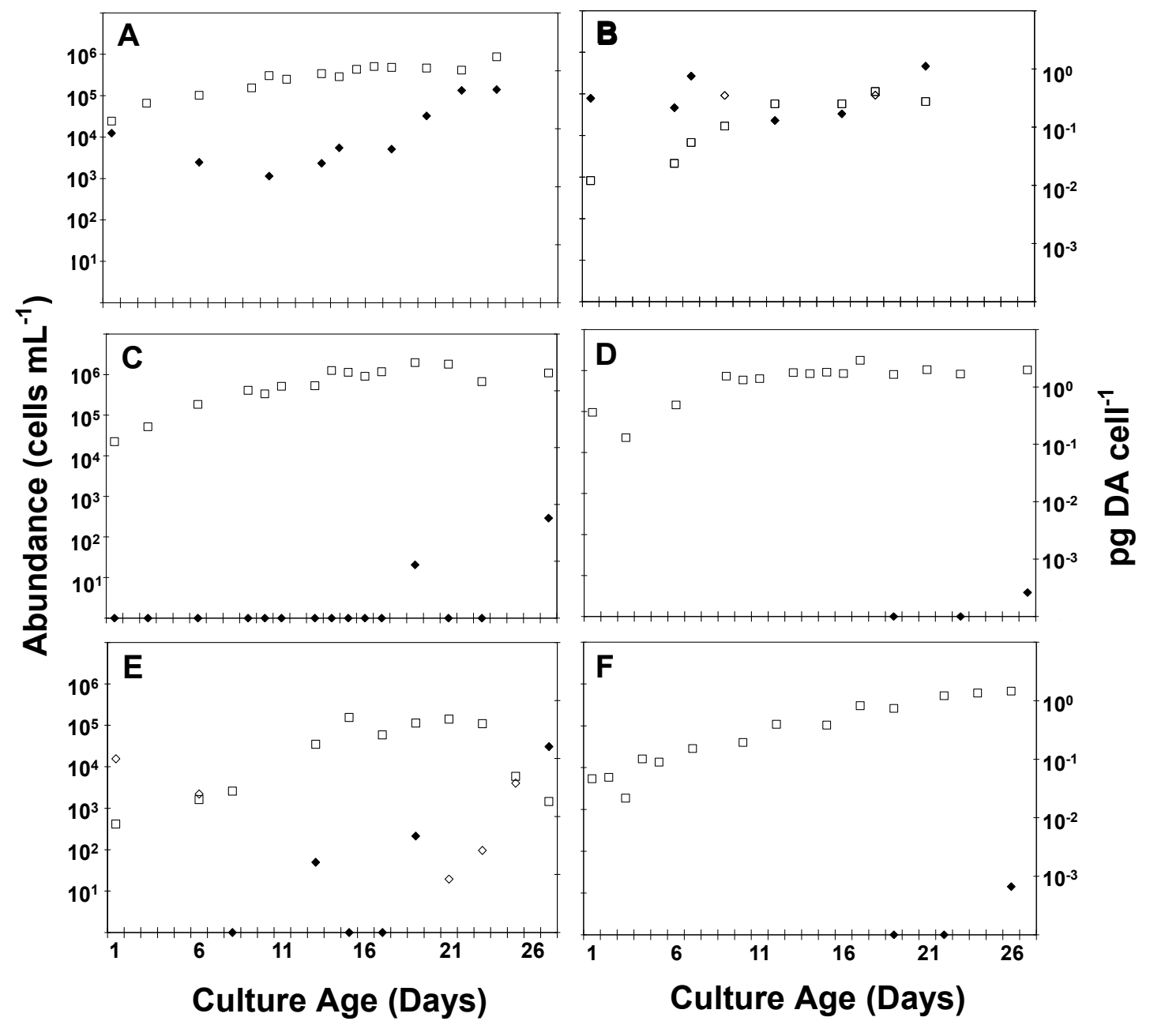


Fig. 5

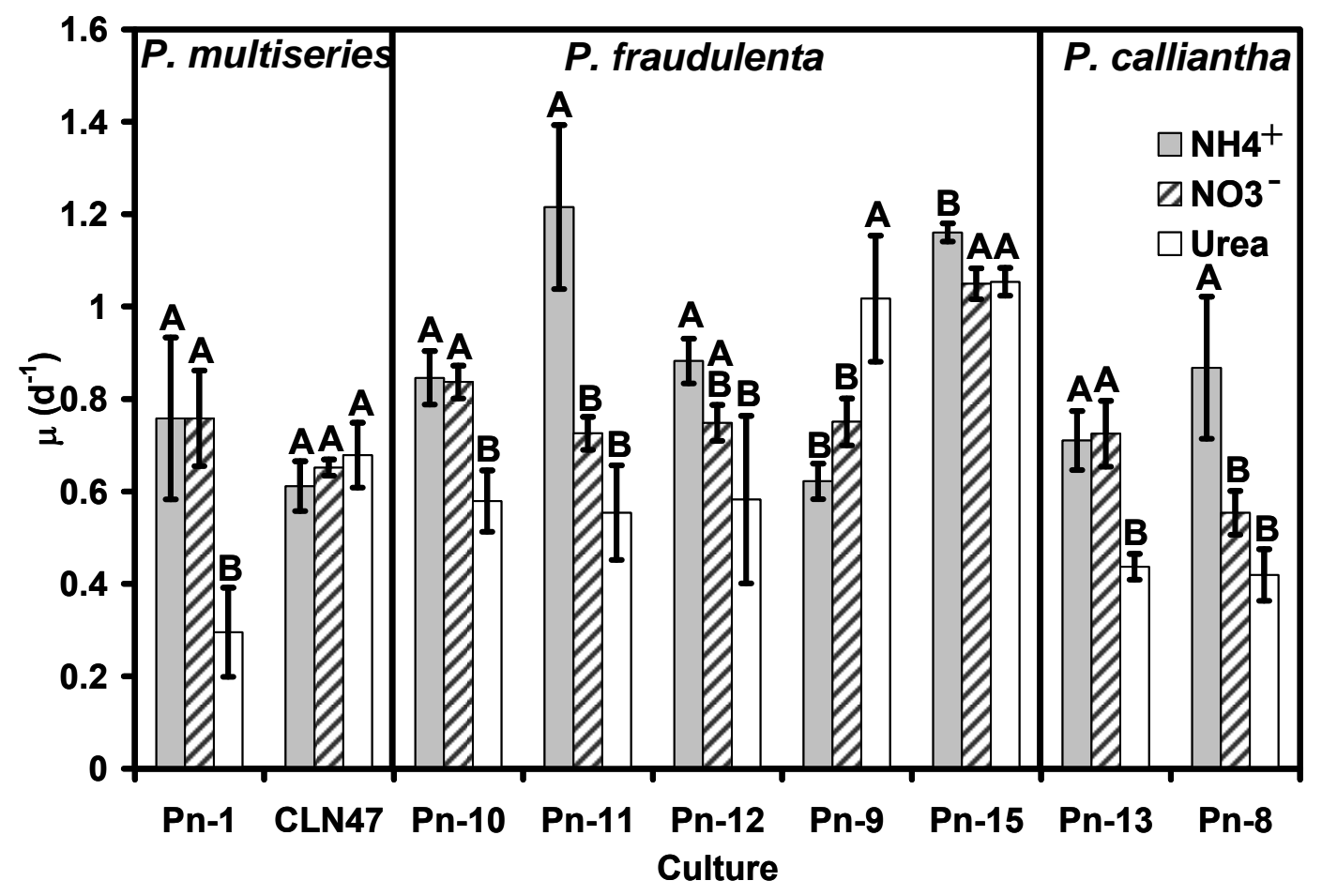


Fig. 6
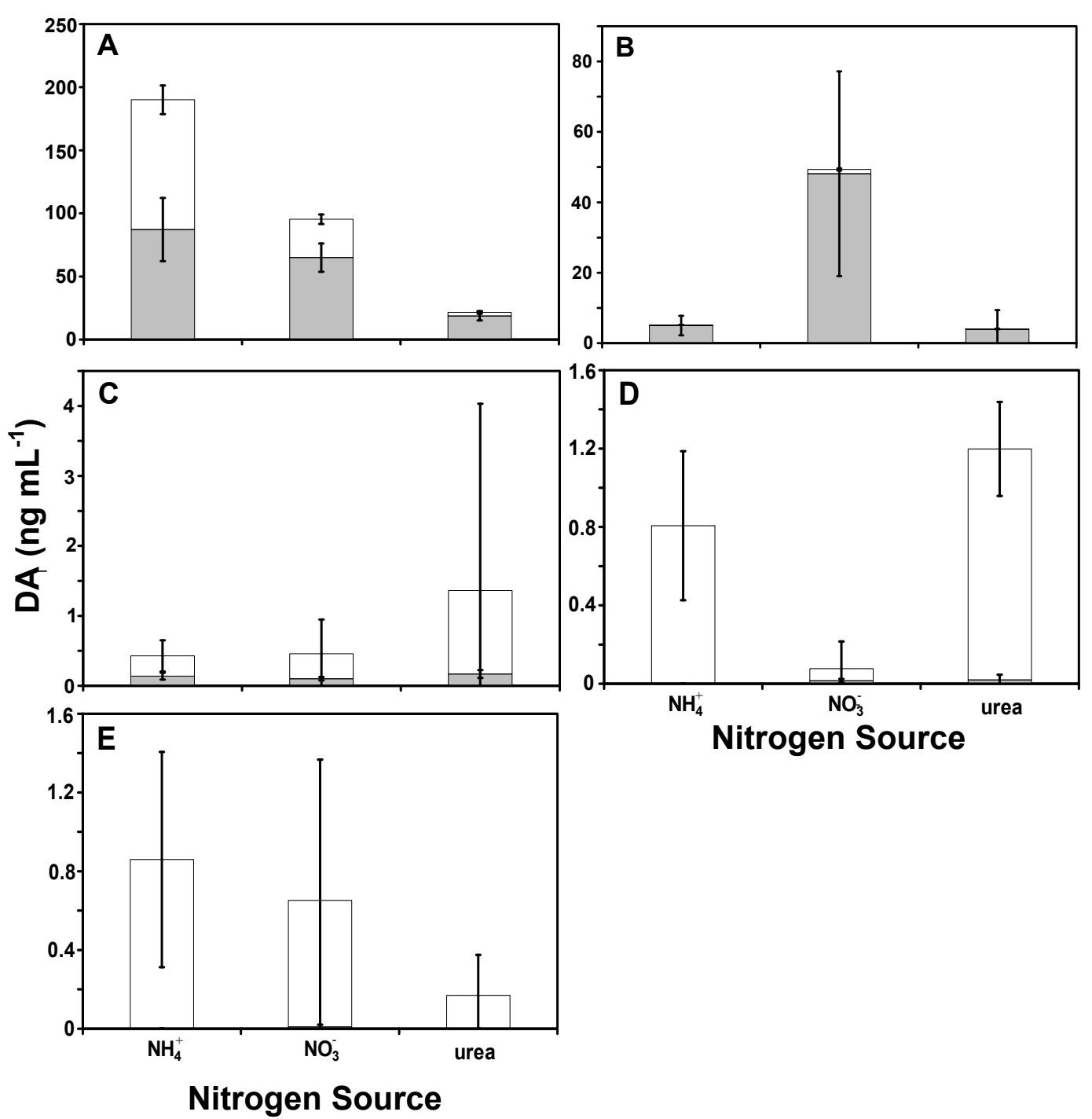
Fig. 7
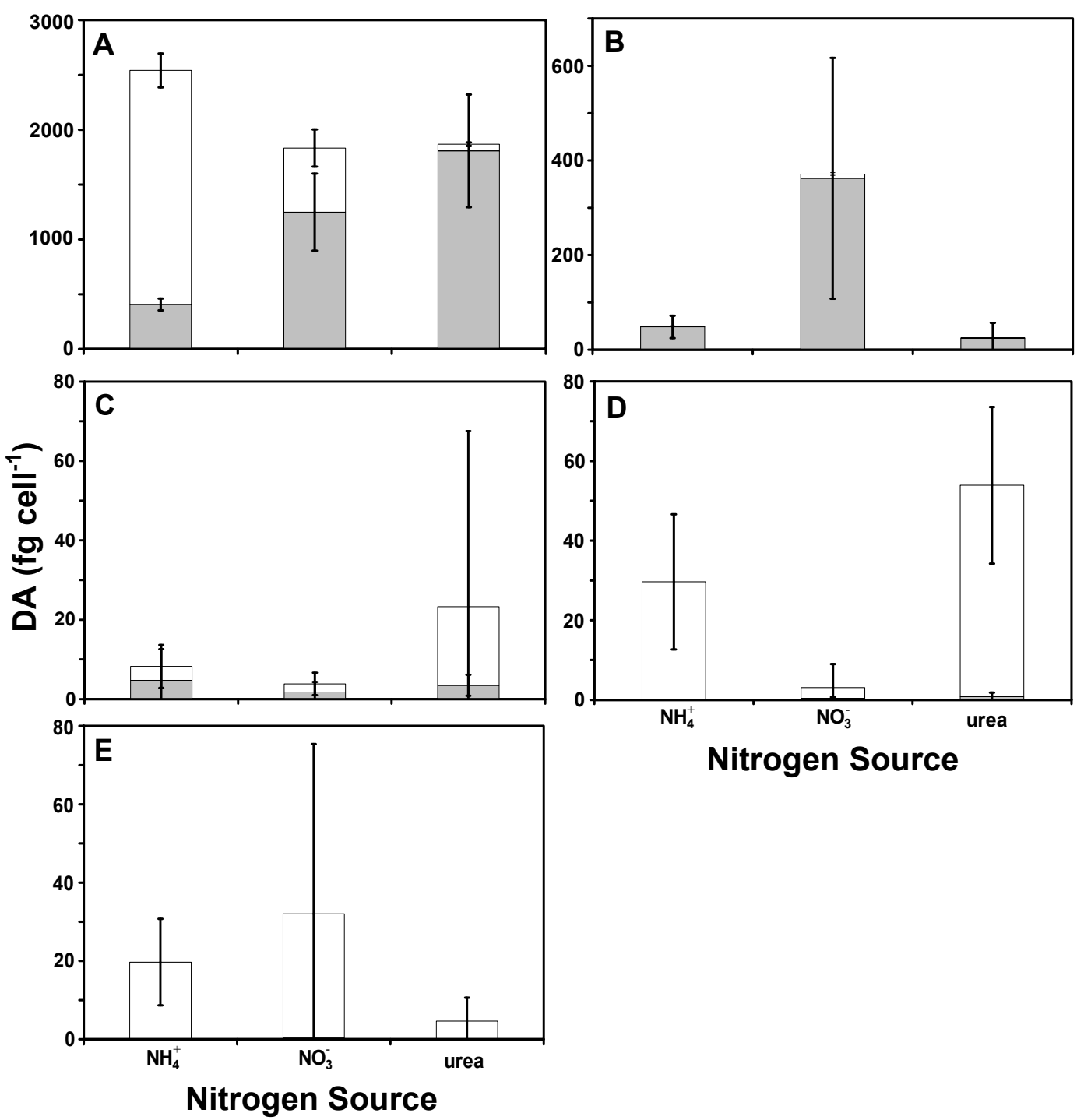

Nitrogen Source 
Fig. 8
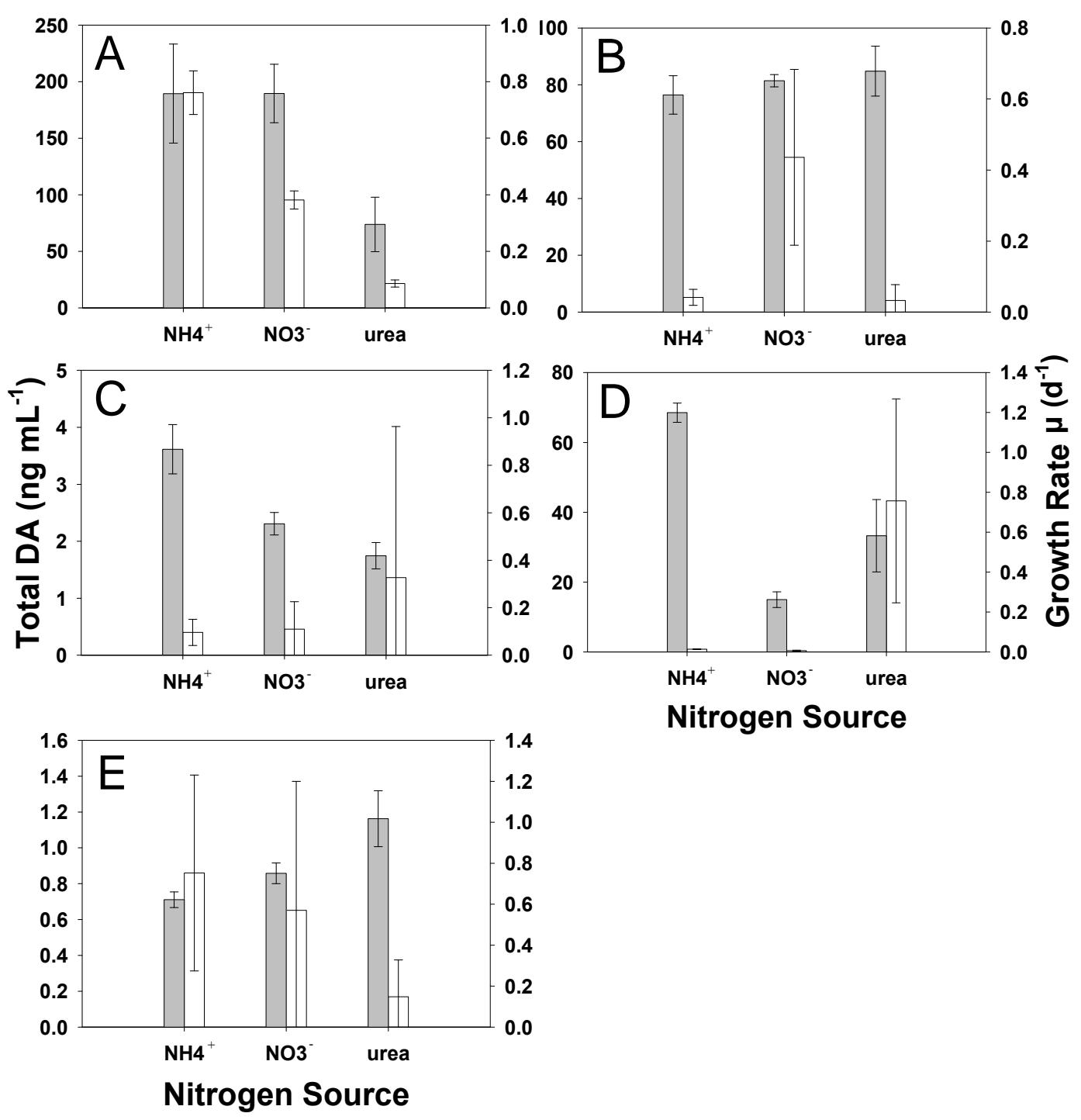

Nitrogen Source 
Fig. 9
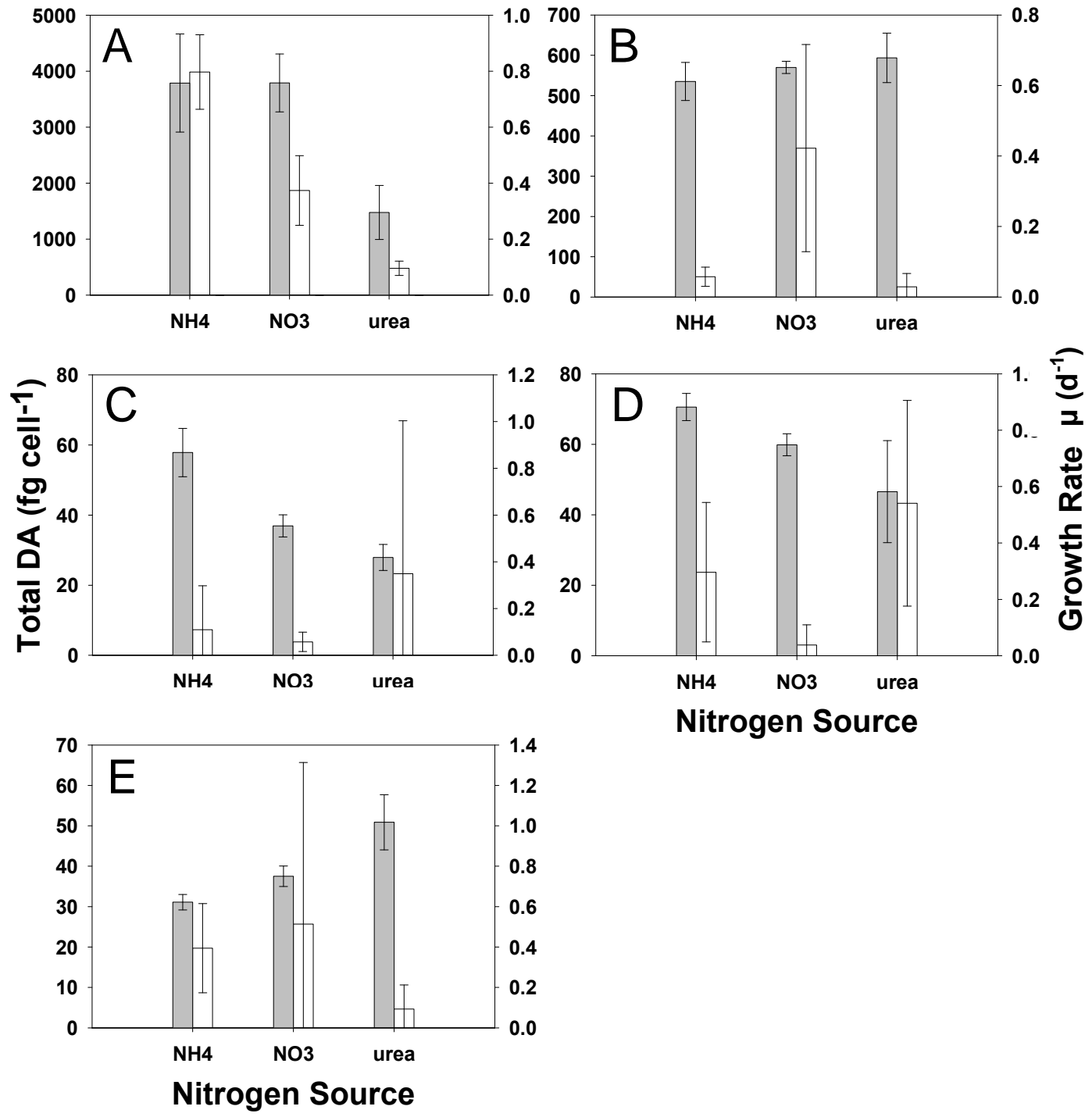

Nitrogen Source 
Fig. 10

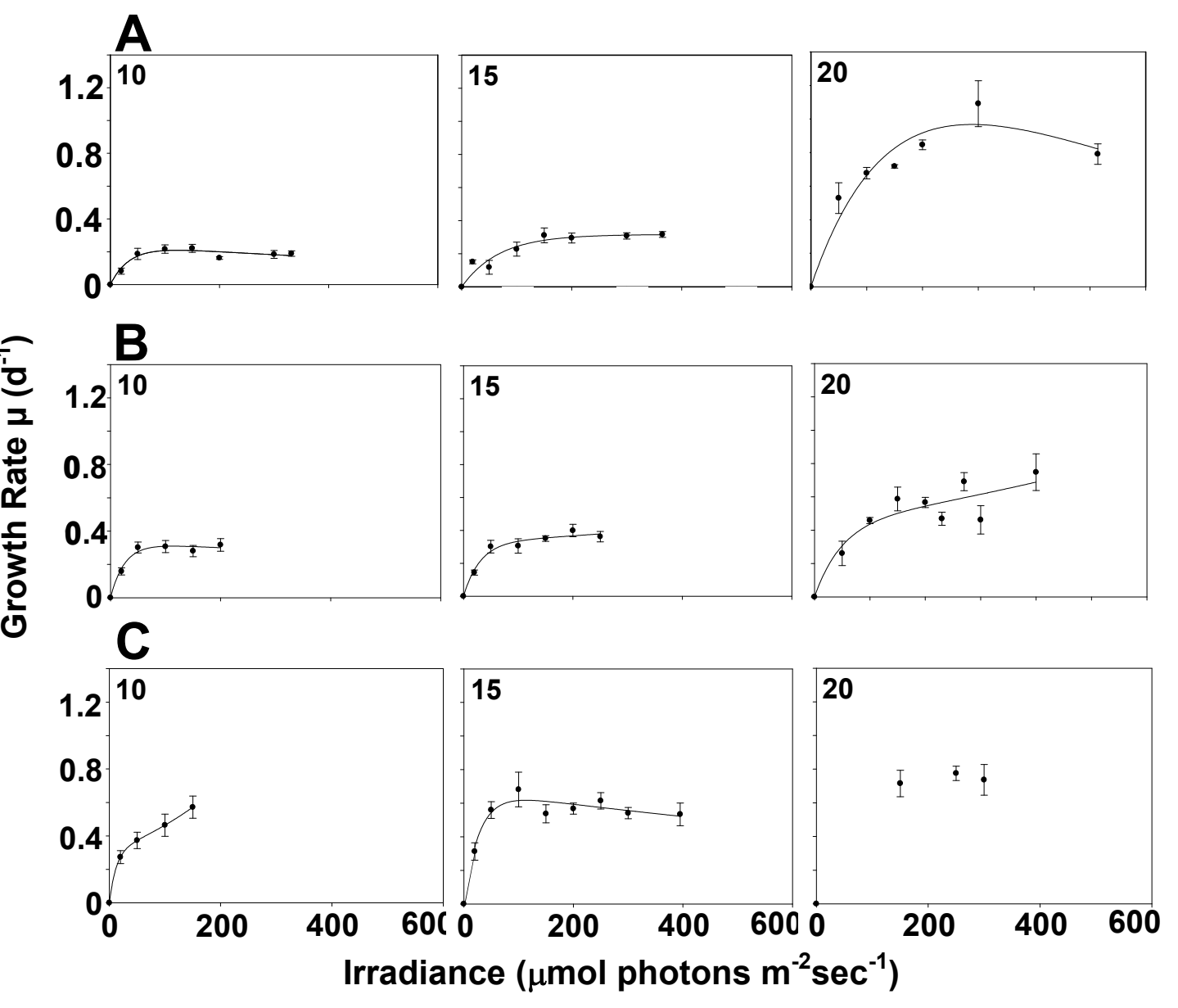

